\title{
Evidence for somatic gene conversion and deletion in bipolar disorder, Crohn's disease, coronary artery disease, hypertension, rheumatoid arthritis, type-1 diabetes, and type- 2 diabetes
}

Kenneth Andrew Ross

\begin{abstract}
Background: During gene conversion, genetic information is transferred unidirectionally between highly homologous but non-allelic regions of DNA. While germ-line gene conversion has been implicated in the pathogenesis of some diseases, somatic gene conversion has remained technically difficult to investigate on a large scale.
\end{abstract}

Methods: A novel analysis technique is proposed for detecting the signature of somatic gene conversion from SNP microarray data. The Wellcome Trust Case Control Consortium has gathered SNP microarray data for two control populations and cohorts for bipolar disorder (BD), cardiovascular disease (CAD), Crohn's disease (CD), hypertension (HT), rheumatoid arthritis (RA), type-1 diabetes (T1D) and type-2 diabetes (T2D). Using the new analysis technique, the seven disease cohorts are analyzed to identify cohort-specific SNPs at which conversion is predicted. The quality of the predictions is assessed by identifying known disease associations for genes in the homologous duplicons, and comparing the frequency of such associations with background rates.

Results: Of 28 disease/locus pairs meeting stringent conditions, 22 show various degrees of disease association, compared with only 8 of 70 in a mock study designed to measure the background association rate $\left(P<10^{-9}\right)$. Additional candidate genes are identified using less stringent filtering conditions. In some cases, somatic deletions appear likely. RA has a distinctive pattern of events relative to other diseases. Similarities in patterns are apparent between BD and HT.

Conclusions: The associations derived represent the first evidence that somatic gene conversion could be a significant causative factor in each of the seven diseases. The specific genes provide potential insights about disease mechanisms, and are strong candidates for further study. Please see Commentary:

http://www.biomedcentral.com/1741-7015/9/13/abstract.

\section{Background}

Gene conversion is a process in which genetic information is transferred unidirectionally between highly homologous but non-allelic regions of DNA [1]. The genome contains many pairs of homologous regions, reflecting frequent gene duplication during evolution. Gene conversion is usually triggered by a double strand break (DSB), which can occur during meiosis or

Correspondence: kar@cs.columbia.edu

Department of Computer Science, Columbia University, New York, NY 10027, USA

\section{() Biomed Central}

mitosis [1]. The DSB is repaired using the homologous sequence as the template. In mammalian cells, the sister chromatid is the most frequent conversion substrate [2], typically leading to perfect repair of a DSB. Gene conversion from other sequence, however, can lead to DNA changes. Gene conversion has recently been implicated in a number of diseases, as a source of both inherited and de-novo germ-line mutation [1]. It has been hypothesized that somatic gene conversion is relatively frequent but has escaped attention due to the technical difficulty of measurement [1]. 
An informative example of gene conversion is the IDS gene, located on the X chromosome. Mutations in IDS cause Hunter syndrome. There is a pseudogene IDS2 located $20 \mathrm{~kb}$ from IDS in an inverted orientation relative to IDS, with $88 \%$ overall homology to IDS [3]. $20 \%$ of Hunter syndrome mutations involve structural rearrangements induced by the interaction of the two nonallelic homologous regions $[3,4]$. The rearrangements appear to be independent events, indicating a recurrent mutation rather than common ancestry. Observed rearrangements include deletions, inversions, and gene conversion events $[3,4]$. Among the regions exhibiting gene conversion, a complex pattern of alternating sequence fragments from each of the duplicons is apparent. The IDS2 pseudogene is missing several IDS exons, but exhibits homology with IDS on each side of this 'gap'. Some of the deletion events observed in the IDS gene appear to represent conversion of IDS sequence by IDS2 in the vicinity of this gap, leading to the elimination of those exons [4]. A one kilobase recombinational hotspot has been identified for the IDS/IDS2 events; this hotspot exhibits $98 \%$ identity compared with the $88 \%$ overall identity of the duplicons [3]. Lagerstedt et al. [3] suggest that recombination is initiated in this high-identity region, and spreads through branch migration until a region of sufficient sequence divergence is reached. Lagerstedt et al. propose a model in which gene conversion leads to changes in both duplicons, and in which mismatched base pairs in the heteroduplex DNA may be corrected to generate additional conversion [3]. Figure 1 illustrates this model. These observations lead to two important conclusions. First, when looking for evidence of gene conversion, one should examine all duplicons for a given sequence. Second, one should examine the entire contiguous high-homology sequence in those duplicons, and not limit the analysis to the immediate neighborhood of a particular locus.

Somatic gene conversion can have multiple kinds of effects. Most obviously, conversion of a coding sequence by a non-identical homologous sequence may lead to a dysfunctional gene product, or an immunogenic novel amino acid sequence. Conversion of a regulatory, promoter, suppressor, or enhancer sequence may alter gene expression, either up or down. Since converted sequence usually retains the methylation status of the source sequence [5], conversion may result in either the methylation of previously unmethylated promoter sequence, suppressing gene expression, or in the demethylation of previously methylated sequence, enabling gene expression where it was not previously expressed. Gene conversion may also be correlated with other effects of nonallelic homologous pairing. Crossover and conversion occur in the same hot spot regions, and gene conversion appears to be preferred over crossover when interacting regions are short [6]. Non-allelic crossover may lead to insertions, deletions and/or inversions. Homologous pairing within a short region of DNA could create DNA loop structures that alter transcription patterns [7]. Conversion could potentially occur during DNA/RNA pairing $[8,9]$. Any of the effects mentioned above could have a major impact on cell function, and provide plausible causative mechanisms for disease.

I propose to examine somatic gene conversion in the context of disease using single nucleotide polymorphism (SNP) microarray data. Because conversion tracts are short, linkage disequilibrium (LD) between a gene conversion locus and nearby SNP markers is likely to be weak or nonexistent [10]. As a result, it becomes necessary to analyze single-SNP markers without expecting to see correlated patterns in nearby markers as one would expect in a traditional disease association study.

The Wellcome Trust Case Control Consortium (WTCCC) data set was obtained using an Affymetrix $500 \mathrm{~K}$ platform [11]. Genotyping was performed on two large British control populations (58C, NBS), in addition to disjoint populations for bipolar disorder (BD), Crohn's disease (CD), coronary artery disease (CAD), hypertension (HT), rheumatoid arthritis (RA), type-1 diabetes (T1D) and type-2 diabetes (T2D). The WTCCC data has been extensively analyzed using a traditional genomewide association study [11]. This previous analysis required the presence of three concordant SNP markers in order to identify a disease-associated haplotype. Such an analysis is likely to miss gene conversion events because of the weak LD. Further, by focusing the analysis at the called-genotype level, such an analysis is insensitive to somatic changes to the genome.

DNA samples in the WTCCC study are obtained from lymphocytes. One might be concerned that an analysis of somatic mutation in lymphocytes may not be informative about somatic mutation in other tissues more closely associated with the diseases in the WTCCC study. Fortunately, there is some evidence that a phenomenon related to gene conversion known as sister chromatid exchange (SCE) is informative about disease when measured in lymphocytes. SCE involves crossover between homologous sister chromatids mediated by the homologous recombination pathway [12], and has been interpreted as indicating general genome instability and/ or a response to DNA damage [13]. SCE is elevated in lymphocytes of individuals with CD [14], CAD [15], T1D [16], and T2D [17], but not RA [18], although in some cases the elevation may be related to treatment rather than disease [19]. SCE is also elevated in multiple sclerosis [20], systemic lupus erythematosus [21], several cancers [14], and in individuals with viral infections [22].

Since SCE analysis using lymphocytes (rather than tissues directly affected by the disease) is informative, one 


\section{Original sequence (color shows homology with template sequence below)}

Homologous (but non-allelic) template sequence

\section{Original sequence experiences double strand break}

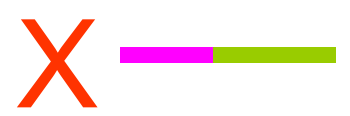

\section{Formation of heteroduplex intermediate}

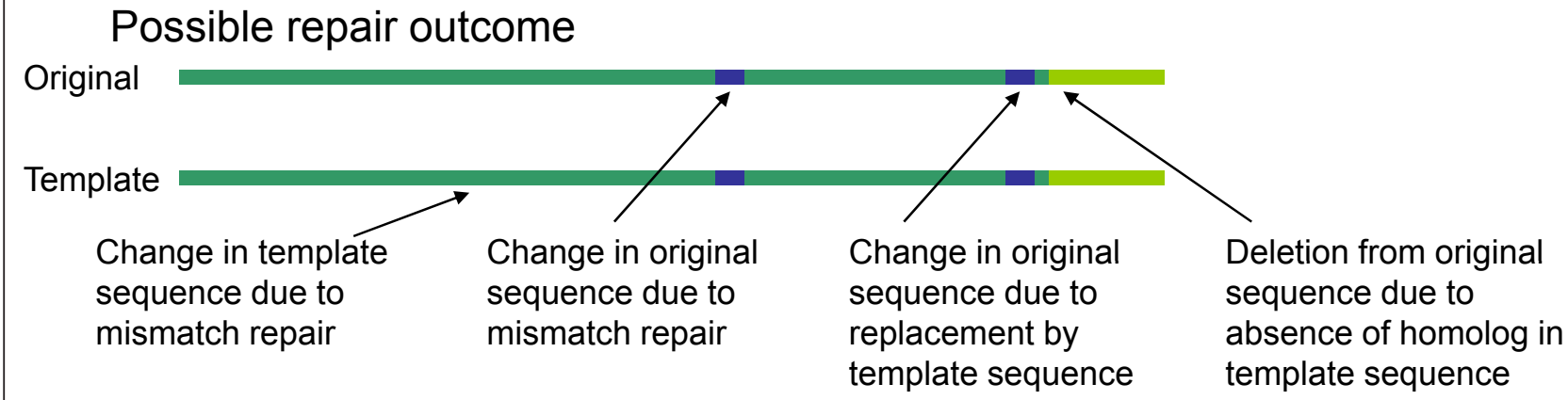

Figure 1 A model of gene conversion between duplicons. Two homologous but non-allelic sequences are shown, with homology indicated by a common green color. After a double strand break in the original sequence, the template sequence is used to form a heteroduplex DNA structure with the original sequence during the process of repair. A possible repair outcome is shown, illustrating changes to both the template and original sequences far from the location of the break, as well as changes and deletion in the original sequence in the vicinity of the break.

might expect lymphocytes to also show disease-associated gene conversion behavior. Because blood cells are widely circulating, they are likely to encounter agents of double strand breakage such as viruses, and therefore exhibit gene conversion if conversion is occurring anywhere in the body. Further, a disease may be associated with damage to a particular tissue, for example by autoimmune processes, and the destroyed tissue is unavailable for analysis. Other cell types such as lymphocytes might therefore serve as useful proxies for damaged tissues. If the mechanisms of in-vivo gene conversion are sequence-specific rather than tissue-specific, then lymphocytes would exhibit the same conversion experienced by the damaged tissue, without eliciting the destruction response.

To identify somatic changes in a population I propose a novel data analysis technique. The technique takes advantage of the fact that a sample contains DNA from many cells of a single individual. If a significant proportion of those cells have undergone gene conversion at a locus, then the resulting change in the genotype of those cells should be measurable as a perturbation in the intensity for the two allele probes at that locus. An SNP with a distribution of perturbations specific to a disease population serves as a marker for a potential disease-associated locus. More details about how such perturbations are measured, and why such perturbations would have a signature different from other sources of variation such as paralogous sequence variants, can be found in the Methods section below.

Once a set of SNPs showing the signature of gene conversion is identified in a disease population, it would be desirable to validate those associations using an independent source of information that links the disease to 
those SNPs significantly more closely than to randomly chosen SNPs. As noted above, one needs to consider not just the SNP locus itself, but all regions with homology to the duplicon containing the SNP. The most direct form of association between a region and a disease is to find a gene in the region that is known to be associated with the disease, or that participates in a critical pathway known to be relevant for the disease. Additional evidence might include data showing that the gene is expressed in the relevant tissue with function related to disease pathogenesis. Most regions of high homology contain at most a few genes, and so the analysis can be relatively specific. One could also look for adjacent genes for which the duplicon could plausibly contain an upstream enhancer locus. I use $30 \mathrm{~kb}$ as a threshold for this type of adjacency.

When duplicons are nearby on the same chromosome, the intermediate region between them is an additional region of interest. Improper recombination between such regions could lead to inversions, insertions, or deletions of the intermediate sequence. In some situations, somatic deletion of a genomic region can generate patterns similar to those that would be generated by gene conversion. Deletion might be suspected when the duplicons occur in an aligned fashion nearby on the same chromosome, a configuration that could lead to misaligned recombination.

In the presence of an agent that induces genetic damage, a cell may respond by inducing the homologydirected repair pathway [23]. If this pathway is induced in each of many cells in response to the same agent, the same homology-biased mutations may happen in a variety of tissues. Mutations in stem cells will persist in lineages descending from those cells.

The damage-initiating agent may act locally or globally. A local agent, such as a virus that damages DNA in a position-specific manner, could induce gene conversion selectively in the region surrounding the target sequence. A global agent, such as a deficient or inactivated DNA repair pathway [24], would lead to DNA damage in a broad (but not necessarily random) fashion, inducing generalized gene conversion at many loci. Local gene conversion will be identifiable as a perturbation in the disease population that is absent in the control population and other disease populations. Perturbations due to global gene conversion may be present, to a lesser degree, in other populations whose diseases are caused by global agents. The perturbations should presumably be absent in the control population and in populations for diseases caused exclusively by local agents.

Increased SCE exchange rates are likely to be correlated with a global causative agent. Based on the SCE data for five of the seven studied diseases [14-18], one might hypothesize that RA is caused by a local agent, while $\mathrm{CD}, \mathrm{CAD}, \mathrm{T} 1 \mathrm{D}$, and $\mathrm{T} 2 \mathrm{D}$ are caused by global agents. This hypothesis will be evaluated in the following analysis.

\section{Methods}

Raw signal intensity and genotype calling data were obtained from the WTCCC in an anonymized form, and the analysis of the data was approved by a Columbia Institutional Review Board. Each disease cohort contained approximately 2,000 individuals, while the two control cohorts each contained approximately 1,500 individuals. The Affymetrix platform supports 500,568 SNP loci, of which 459,653 passed the WTCCC quality control procedures [11].

For a SNP locus with an A/B polymorphism, the microarray generates a pair of intensity values $I_{A}$ and $I_{B}$. Each intensity value is the average intensity over a small number of oligonucleotide probes containing the allele together with some flanking sequence. The $\left(I_{A}, I_{B}\right)$ point typically falls within one of three clusters corresponding to the three genotypes $\mathrm{AA}, \mathrm{AB}$, and $\mathrm{BB}$.

Consider now an individual with an AA genotype. Suppose that $20 \%$ of the sampled cells of this individual have undergone gene conversion in which one of the A alleles has been converted into a B allele by a homologous sequence, while the flanking sequence has remained unchanged. The left example of Figure 2 shows this kind of conversion. (Conversion of both A alleles would be rare, and is ignored.) This individual will display an overall $\left(I_{A}, I_{B}\right)$ intensity pair that is $20 \%$ of the way from the $\mathrm{AA}$ cluster to the $\mathrm{AB}$ cluster. In another individual with a heterozygous $A B$ genotype, a $20 \%$ conversion rate at the same locus would yield an overall $\left(I_{A}, I_{B}\right)$ intensity pair that is $10 \%$ of the way from the $A B$ cluster to the $B B$ cluster, since only the conversion of the $\mathrm{A}$ allele will cause a change in probe intensities. In an individual with a BB genotype, no change would be observed.

Because there is experimental variation in intensity measurements, it may be difficult to determine whether a small perturbation in a single measurement represents gene conversion or merely noise. However, it is possible to study the distribution of perturbations for a population at a locus. If a population has a significant spread of intensities between clusters, when control populations do not, then one can hypothesize that gene conversion at that locus is happening in a population-specific manner. See the cluster plot for RA in Figure 3 for an example. If the population is a disease cohort, then the locus may be associated with the disease phenotype.

Returning to the example above, consider the complementary situation in which the flanking sequence near an SNP probe has been converted. Whether or not the 


\title{
SNP probe sequences (25bp, color shows homology)
}

\author{
Allele A \\ Allele B

\section{SNP locus sequences (in an AA homozygote)}

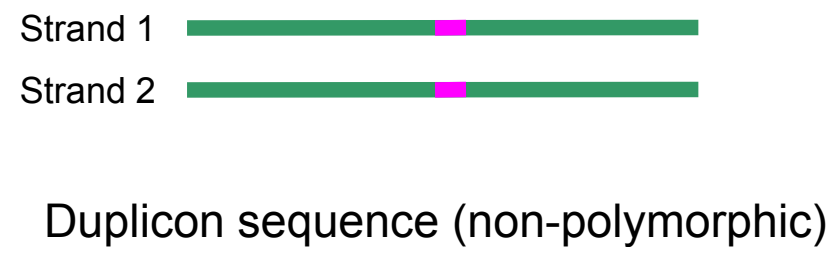

Case 1, flanking sequence matches probe

Case 2, flanking sequence does not match probe

\section{Possible SNP locus conversion outcomes}

Strand 1

Strand 2

\section{lower A signal, higher B signal}

Figure 2 Effects of gene conversion on probe intensity signals. A microarray has two probes for a SNP, each 25 bp long (top). An individual with an AA homozygous genotype at the SNP locus is shown. Two examples of gene conversion are illustrated. The left example considers the case when the duplicon contains sequence that exactly matches the B probe. The right example considers the case when the duplicon contains sequence that does not match either probe.

SNP locus is changed, the converted sequence will no longer match either probe sequence. The right example of Figure 2 shows this kind of conversion. If many cells in an individual are converted in this fashion, a reduced signal from this sequence will be measured by both probes of the microarray. For a locus at which this effect is associated with the disease phenotype, all clusters will shift radially towards the origin in the cluster plots for the disease population.

Calling algorithms attempt to identify the boundaries of clusters corresponding to the $\mathrm{AA}, \mathrm{AB}$ and $\mathrm{BB}$ genotypes. For example, the Chiamo algorithm [11], considers all populations simultaneously, and estimates cluster boundaries in a way that allows for some populationdependent differences. The intensity distributions vary from SNP to SNP, and so clustering is performed separately for each SNP.

Based on the analysis above, gene conversion for a particular population should be accompanied by either (a) an increase in the spread of the two-dimensional intensity distribution relative to the control population,
Strand 1

Strand 2

\section{lower A signal, unchanged B signal}

or (b) a translation of the clusters towards the origin, relative to the control population. In case (a), there should be an increase in the number of points that are either between clusters, or on the fringe of a cluster. In case (b), there should be a decrease in the distance between clusters, leading to an increase in the number of points whose cluster assignment is ambiguous. Either way, there will be an increase in the number of no-calls generated by the calling algorithm, relative to the control populations. This is one 'signature' of gene conversion that I will try to identify.

The Chiamo calling algorithm has been applied to the WTCCC data, and it is possible to use those calls to help recognize the signature of gene conversion. Chiamo generates a confidence score for a call; the authors of the Chiamo algorithm recommend that when this score is below 0.9 , the genotype should be considered a 'nocall.' When clusters are more dispersed, their peripheries can begin to overlap with each other. In such a situation, the Chiamo algorithm will have less certainty about points falling in the intermediate regions. Chiamo 


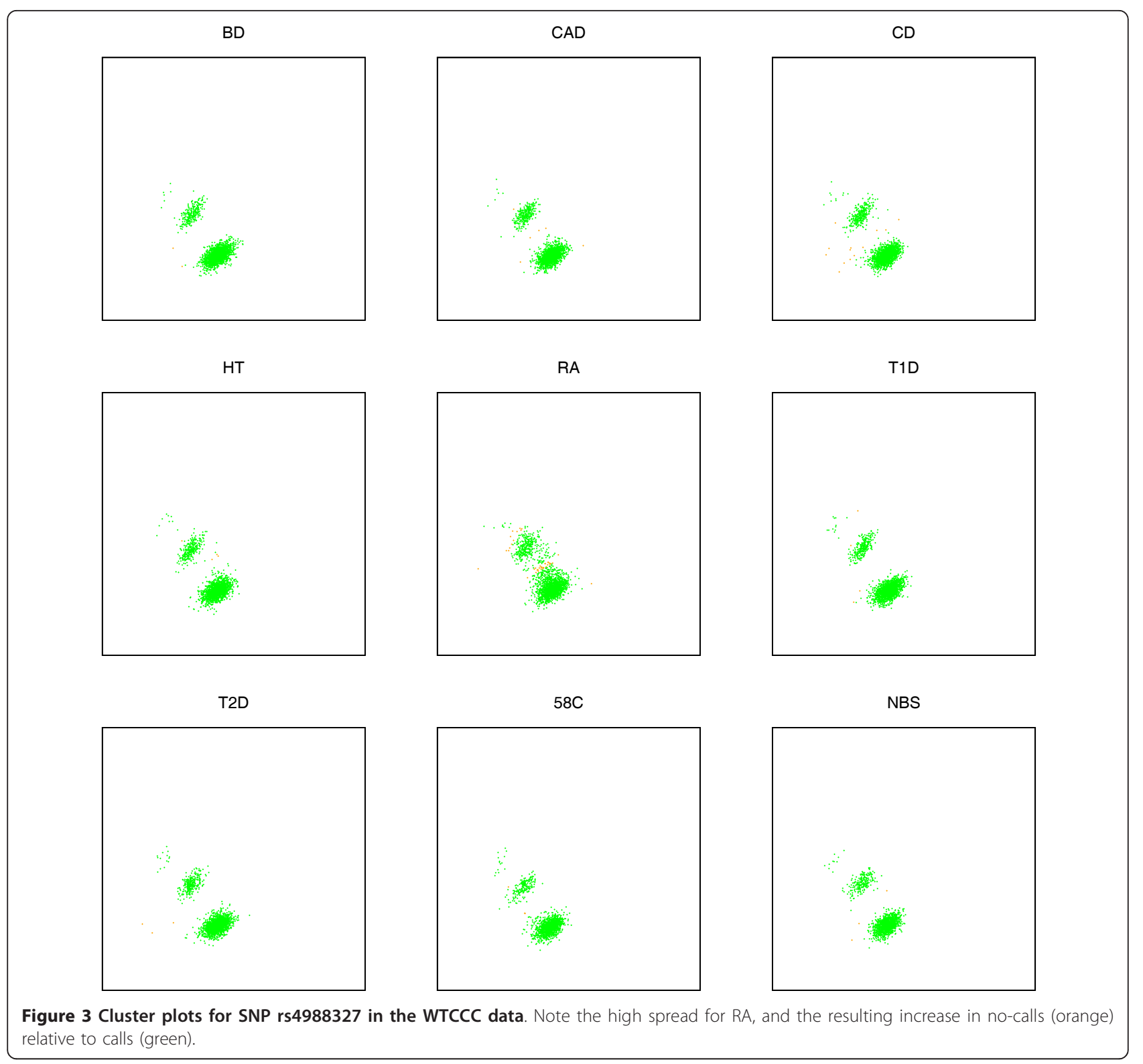

will define cluster boundaries more tightly, resulting in an increase in the no-call rate for intermediate points [11]. An example of this phenomenon is given in Figure 3 , where the orange points (that are particularly frequent in RA at this locus) are no-calls.

An increase in no-calls between two clusters can lead to a biased allele distribution in the called genotypes. For example, if there are many no-calls between the AA and $A B$ clusters, then the $A$ allele will be underrepresented among the subpopulation whose genotypes are called with high confidence. This bias is another possible signature for gene conversion. (See Additional file 1 for an extended discussion of no-calls.) Note that there may be cases of gene conversion that do not show this signature because the non-called points do not change the observed allele frequencies.

To identify gene conversion events, I take three complementary approaches. The first approach that I call the 'stringent' filter is designed to optimize precision, that is, to minimize the number of false positives while possibly missing some true positives. The second approach is designed to provide better recall, that is, to include more true positives at the risk of also including false positives. This second approach is called the 'relaxed' filter. The third approach, termed the 'no-callonly' filter, looks only for extreme no-call rates, since some gene conversion loci may not exhibit changes in called allele frequencies. 
For the stringent filter, called SNPs with high no-call rates in a population relative to the union of the two control populations are initially selected. A chi-squared statistic is calculated for each SNP based on a $2 \times 2$ chisquared test comparing calls/no-calls for both the disease population and the control population. Only SNPs with an increase in the no-call rate in the disease population and a chi-squared statistic corresponding to $P<5 \times 10^{-5}$ in a one-sided test are retained by this initial selection.

A further selection is applied to test for a bias in the genotype distribution in the disease population relative to controls. Bias is assessed in one of two ways; an SNP that displays bias according to either of these tests is retained. Only SNPs in which the control population has at least ten individuals for each of the $\mathrm{AA}, \mathrm{AB}$ and $\mathrm{BB}$ genotypes are considered. First, the three genotype frequencies in the disease population are compared with the corresponding frequencies in the control population using a $3 \times 2$ chi-squared test to determine the likelihood that they have a common distribution. Only SNPs with a chi-squared statistic corresponding to $P<5 \times$ $10^{-4}$ in a two-sided test are retained. Second, the three genotype frequencies in the disease population and control population are separately assessed for departure from Hardy-Weinberg Equilibrium using a conventional $3 \times 2$ chi-squared test. Only SNPs with a chi-squared statistic corresponding to $P<5 \times 10^{-4}$ in a two-sided test in the disease population and a chi-squared statistic corresponding to $P>0.01$ in the control population are retained.

Gene conversion appears to require at least 300 base pairs of homology in humans [1]. Among known gene conversion loci, the smallest degree of identity between the homologous regions is $88 \%$ [1]. One should therefore not expect newly discovered loci to have identity much below $88 \%$. I will thus use $85 \%$ identity as a lower bound for the stringent filter.

The candidate SNPs were evaluated for homologous flanking sequence elsewhere in the genome. The UCSC database of segmental duplications [25] was used to identify genomewide duplications with at least 1,000 base pairs of homology (after elimination of lowcomplexity repeats) and at least 90\% identity. Additionally, each SNP that met the other stringent filter conditions was subjected to manual analysis using the BLAST network service at NCBI to identify duplications that may not meet the thresholds of the segmental duplication database, but that may still be relevant for gene conversion. (I used the Megablast algorithm with default parameters. When a duplicon contains several almostcontiguous segments, the identity of the duplicon is the identity reported by BLAST for the segment containing the region that maps to the SNP under consideration.)
The three filters are summarized in Table 1. The relaxed and no-call filters use different homology criteria from the stringent test so that the segmental duplication database can be used to automate the analysis. Because the segmental duplication database excludes regions with low complexity repeats, some SNPs in regions with more than 90\% homology (for example, rs9378249) are not in the segmental duplication database.

The analysis does not consider SNPs on the Y chromosome. For the $\mathrm{X}$ chromosome, the analysis is limited to the female subpopulation within each cohort. As a result, some statistical power is lost, particularly for cohorts such as CAD that have a relatively small number of female members.

Cluster plots for all SNPs mentioned in the text can be found in Additional file 2.

\section{Sources of variation}

Copy number variations at an SNP locus mean that in addition to the conventional $\mathrm{AA}, \mathrm{AB}$, and $\mathrm{BB}$ genotypes, there may be additional genotypes such as $\mathrm{AAB}$ and $\mathrm{B}$. Each of these alternative genotypes would have its own cluster in the cluster plot, which can be examined for signs of more than three clusters. Each SNP was also assessed for known copy-number variation using the Database of Genomic Variants [26], since copy-number variants could also cause changes in no-call frequencies and genotype distributions that may be related to disease. (See Additional file 1 for further discussion of copy number variation.) Note that somatic deletion would generate genotypes like B in some cells, but since most cells retain the normal copy number, the effect will be a small perturbation in the cluster plot rather than a separate cluster. Germ-line mutations would not give the same perturbation patterns as somatic conversion. For a germ-line mutation that changed one allele to another, the individual would appear as part of another cluster in the corresponding cluster plot. If a germ-line mutation deleted or duplicated an allele, then the individual would appear as part of a cluster with a nonstandard copy number. If this deletion/duplication was common, then the cluster plot would show features typical of $\mathrm{CNV}$ loci, such as the presence of more than three clusters.

A paralogous sequence variant occurs when the homologous sequence to the mapped SNP sequence

Table 1 Summary of the three data filters

\begin{tabular}{llrc}
\hline Filter & $\begin{array}{c}\text { No-call rate } \\
\text { increase }\end{array}$ & Min. homology & $\begin{array}{c}\text { Biased } \\
\text { distribution }\end{array}$ \\
\hline Stringent & $P<5 \times 10^{-5}$ & $300 \mathrm{bp}, 85 \%$ & $P<5 \times 10^{-4}$ \\
Relaxed & $P<5 \times 10^{-2}$ & $1,000 \mathrm{bp}, 90 \%$ & $P<1 \times 10^{-2}$ \\
No-call only & $P<1 \times 10^{-8}$ & $1,000 \mathrm{bp}, 90 \%$ & - \\
\hline
\end{tabular}


possesses a polymorphism. Suppose an SNP has probes for alleles $\mathrm{A}$ and $\mathrm{B}$. If the paralogous sequence also has an $\mathrm{A} / \mathrm{B}$ polymorphism, then the cluster plot will have five clusters, corresponding to AAAA, AAAB, AABB, $\mathrm{ABBB}$, and $\mathrm{BBBB}$. If the paralogous sequence has an $\mathrm{A} / \mathrm{C}$ polymorphism, then the probes will not detect the signal from the $C$ allele, and there will be clusters for $\mathrm{AA}, \mathrm{AB}, \mathrm{BB}, \mathrm{AAA}, \mathrm{AAB}, \mathrm{ABB}, \mathrm{AAAA}, \mathrm{AAAB}, \mathrm{AABB}$. In either case, the cluster plot will differ significantly from what is expected under a gene conversion hypothesis.

Some polymorphisms on the microarray platform may have been misidentified, with the true polymorphism being in paralogous sequence with no polymorphism at the mapped SNP locus. As long as the paralogous sequence is part of a larger region of homology with the mapped SNP locus, the outcome of the gene conversion analysis will be unchanged by such phenomena because both duplicons are examined.

A foundational somatic mutation could occur during early development, leading to a lineage of cells within the individual carrying the mutation. This kind of mutation will not be identified by the present analysis unless the blood cells being genotyped come from more than one such lineage. Even then, the relevance of a foundational mutation to disease would be unclear because the mutation would also have to have been in a lineage ancestral to the diseased tissue.

\section{Results}

\section{Putative gene conversion events detected using the stringent filter}

31 instances of putative gene conversion with duplicon identity of at least $85 \%$ were identified using the stringent filter, covering 23 distinct SNPs. This data is summarized in Tables 2, 3 and 4; additional information about the associations can be found in Table S1 in Additional file 1. The SNPs in Table 4 fall within the $\mathrm{MHC}$ region and are identified by the stringent filter for T1D. Since T1D has significant associations at the haplotype level in the MHC region [11], it is difficult to separate a conversion signal from the broader association signal for these SNPs. The same is true for RA [11], but no MHC SNPs were identified for RA using the stringent filter.

In all 28 of the 28 instances in Tables 2 and 3, the change in allele frequency is consistent with what would be predicted by a gene conversion hypothesis (see Additional file 1). Additional SNPs that met the stringent filter conditions except that identity between duplicons was $71 \%-83 \%$ are discussed in Additional file 1.

The strength of the evidence for a putative SNP/disease association is determined by consulting the published literature in search of a known association. The strength of the evidence is summarized using the scale of Table 5, where a higher number corresponds roughly to stronger evidence. The score for a SNP is the maximum score for any gene in any duplicon associated with the SNP; genes for which a duplicon occurs $30 \mathrm{~kb}$ or less upstream of the gene are included. Note that the score for an SNP does not give any weight to genes occurring between neighboring homologous regions (except for the $30 \mathrm{~kb}$-upstream genes mentioned above). The evidence score therefore ignores the possible deletion and/or duplication of genes in the intervening sequence. The code for the strength of the evidence is given in parentheses in the heading for each SNP.

To assess the significance of the set of identified regions, the duplicons for the SNPs identified by the stringent test (which should have few false positives) are assessed for association with the corresponding disease. The code for the strength of the evidence is given in parentheses in the heading.

\section{rs4471699 in CD (6)}

Of the characterized genes in the various duplicons, SULT1A3 has the most obvious connection to the CD phenotype involving inflammation of the small and/or large intestine. SULT1A3 is highly expressed in the small intestine [27] where it specifically sulfates dopamine and is important for the metabolism of several neurotransmitters [28]. SULT1A3 shows reduced expression in the colons of CD patients [29]. (The related genes SULT1A1 and SULT1A2, which are also located in a segmentally duplicated region of chromosome 16, have reduced expression in CD [30].) Eisenhofer et al. [28] suggest that the production of dopamine sulfate in the intestine 'reflects an enzymatic "gut-blood" barrier for detoxifying dietary biogenic amines.' Dysfunction of this pathway could lead to toxicity in the small and large intestines.

The UQCRC2 gene is a part of the mitochondrial respiratory complex III. Apolipoprotein E4 binds to UQCRC2, and overexpression of a fragment of this protein impairs the function of complex III [31]. Mitochondrial dysfunction has been associated with CD in several case reports, including one with dysfunction in complex III [32].

Strikingly, the duplicon containing rs4471699 and the closest matching duplicon have recently been shown to be endpoints of a region deleted in the germ-line in certain cases of autism, and duplicated in others [33,34]. Among the common features of autism are gastrointestinal abnormalities [35]. Mitochondrial dysfunction also occurs with increased frequency in autism [36,37].

\section{rs669980 in RA (5)}

CBWD1 (and by inference also CBWD2) has $25 \%$ protein identity with the cobW gene of P. dentrificans that is thought to be involved in vitamin $B_{12}$ processing [38], and possibly cobalt chelation $[39,40]$. 
Table 2 SNPs identified for various cohorts using the stringent filter (Part 1)

\begin{tabular}{|c|c|c|c|c|c|}
\hline \multirow{2}{*}{$\begin{array}{l}\text { Cohort(s) } \\
C D\end{array}$} & \multirow{2}{*}{$\begin{array}{l}\begin{array}{l}\text { SNP/identity } \\
\text { (degeneracy) }\end{array} \\
\text { rs4471699 }\end{array}$} & \multicolumn{2}{|c|}{$\begin{array}{l}\text { Chr: Pos. (hg17) } \\
\text { and orientation }\end{array}$} & \multirow{2}{*}{$\begin{array}{l}\text { Duplicon } \\
\text { length } \\
147 \mathrm{~kb}\end{array}$} & \multirow{2}{*}{$\begin{array}{l}\text { Characterized genes and } \\
\text { pseudogenes in duplicons } \\
\text { SULT1A3, GIYD2, BOLA2, IMAA, CORO1A }\end{array}$} \\
\hline & & 16: & $30.2 \mathrm{M} \rightarrow$ & & \\
\hline & $99.6 \%$ & 16: & $29.4 \mathrm{M} \rightarrow$ & $146 \mathrm{~kb}$ & SULT1A3, GIYD2, BOLA2, IMAA, MLAS \\
\hline & $98.1 \%$ & 16: & $21.8 \mathrm{M} \rightarrow$ & $41 \mathrm{~kb}$ & [UQCRC2] \\
\hline & $98.0 \%$ & 16: & $22.3 \mathrm{M} \leftarrow$ & $42 \mathrm{~kb}$ & [NPIPL3] \\
\hline & $98.0 \%$ & 16: & $21.3 \mathrm{M} \rightarrow$ & $42 \mathrm{~kb}$ & IMAA, [NPIPL3] \\
\hline & $97.1 \%$ & 16: & $18.8 \mathrm{M} \rightarrow$ & $75 \mathrm{~kb}$ & SMG1 \\
\hline \multirow[t]{2}{*}{ RA } & rs669980 & 9: & $0.2 \mathrm{M} \rightarrow$ & $193 \mathrm{~kb}$ & CBWD1, FOXD4, FAM138A, WASH1, [DOCK8] \\
\hline & $98.9 \%(F)$ & $2:$ & $114 \mathrm{M} \leftarrow$ & $189 \mathrm{~kb}$ & CBWD2, FOX4DL1, FAM138B, WASH2P, [RABL2A] \\
\hline \multirow[t]{2}{*}{$C A D, T 2 D$} & rs10502407 & 18: & $10.6 \mathrm{M} \rightarrow$ & $52 \mathrm{~kb}$ & - \\
\hline & $97.9 \%$ & 18: & $12.2 \mathrm{M} \leftarrow$ & $64 \mathrm{~kb}$ & [CIDEA] \\
\hline \multirow[t]{2}{*}{$C A D$} & rs12134625 & 1: & $78 \mathrm{M} \rightarrow$ & 931 & - \\
\hline & $97.0 \%$ & 1: & $24 \mathrm{M} \leftarrow$ & 932 & FUSIP1 \\
\hline $\mathrm{BD}, \mathrm{CAD}$ & rs9551988 & 13: & $19.2 \mathrm{M} \rightarrow$ & $2.6 \mathrm{~kb}$ & PSPC1 \\
\hline HT & $96.2 \%(F)$ & 13: & $18.7 \mathrm{M} \rightarrow$ & $2.8 \mathrm{~kb}$ & [TUBA3C] \\
\hline \multirow[t]{2}{*}{ HT } & rs935019 & $2:$ & $127,162 \mathrm{~K} \rightarrow$ & $3.6 \mathrm{~kb}$ & GYPC \\
\hline & $95.3 \%(F)$ & $2:$ & $127,166 \mathrm{~K} \rightarrow$ & $3.5 \mathrm{~kb}$ & GYPC \\
\hline \multirow[t]{2}{*}{ HT } & rs12227938 & 12: & $37 M \rightarrow$ & $154 \mathrm{~kb}$ & ALG10B \\
\hline & $95.3 \%(P)$ & 12: & $34 \mathrm{M} \rightarrow$ & $127 \mathrm{~kb}$ & ALG10 \\
\hline \multirow[t]{2}{*}{$\mathrm{T} 2 \mathrm{D}$} & SNP_A-1797773 & 16: & $45 \mathrm{M} \rightarrow$ & $14 \mathrm{~kb}$ & VPS35, [ORC6L] \\
\hline & $94.8 \%(F)$ & 16: & $34 \mathrm{M} \leftarrow$ & $16 \mathrm{~kb}$ & - \\
\hline \multirow[t]{12}{*}{$\mathrm{T} 1 \mathrm{D}$} & rs12381130 & 16: & $5 \mathrm{M} \rightarrow$ & $88 \mathrm{~kb}$ & ALG1, FAM86A \\
\hline & $94.7 \%$ & 3: & $127 \mathrm{M} \leftarrow$ & $76 \mathrm{~kb}$ & ALG1L \\
\hline & $94.6 \%$ & 11: & $67 M \rightarrow$ & $79 \mathrm{~kb}$ & - \\
\hline & $94.6 \%$ & 11: & $71 \mathrm{M} \leftarrow$ & $40 \mathrm{~kb}$ & FAM86C, [DEFB108B] \\
\hline & $94.5 \%$ & 11: & $3 \mathrm{M} \rightarrow$ & $91 \mathrm{~kb}$ & [ZNF195] \\
\hline & $94.3 \%$ & 3: & $76 \mathrm{M} \rightarrow$ & $44 \mathrm{~kb}$ & [FAM86D] \\
\hline & $94.0 \%$ & 4: & $9 \mathrm{M} \leftarrow$ & $120 \mathrm{~kb}$ & - \\
\hline & $93.9 \%$ & 3: & $131 \mathrm{M} \rightarrow$ & $44 \mathrm{~kb}$ & - \\
\hline & $93.9 \%$ & 4: & $4 \mathrm{M} \rightarrow$ & $53 \mathrm{~kb}$ & - \\
\hline & $93.7 \%$ & 12: & $8 \mathrm{M} \rightarrow$ & $53 \mathrm{~kb}$ & [FAM90A1] \\
\hline & $93.6 \%$ & 8: & $12 \mathrm{M} \rightarrow$ & $41 \mathrm{~kb}$ & [FAM86B1] \\
\hline & $93.5 \%$ & 8: & $8 \mathrm{M} \leftarrow$ & $63 \mathrm{~kb}$ & - \\
\hline
\end{tabular}

Multiple almost-contiguous segmental duplications are treated as a single large duplicon (intervening sequence is included in the length). The table includes only duplicons with at least $85 \%$ identity to the region containing the SNP. Duplicons with identical flanking sequence to the SNP are labeled as fully degenerate (F); duplicons with partial degeneracy are labeled (P). Characterized genes are listed if they occur within a duplicon. Genes in square brackets are outside the duplicon, but the duplicon is at most 30 kb upstream of the gene. Genes for a SNP are italicized if the SNP is within that gene, or if the SNP maps to a position within that gene in the duplicon.

Vitamin $\mathrm{B}_{12}$-binding proteins are found in the synovium of RA patients $[41,42]$. Low serum vitamin $B_{12}$ levels are noted in a significant percentage of RA patients [43]. Methyl $B_{12}$ appears to suppress cytokine production in $\mathrm{T}$ lymphocytes [44], which may be relevant to $R A$. Improper vitamin $B_{12}$ processing can lead to elevated plasma homocysteine levels, which has been observed in multiple RA cohorts [45].

Dysregulation of cobalt chelation could also have secondary mutagenic effects, since cobalt is genotoxic [46]. 
Table 3 SNPs identified for various cohorts using the stringent filter (Part 2)

\begin{tabular}{|c|c|c|c|c|c|}
\hline Cohort(s) & $\begin{array}{l}\text { SNP/identity } \\
\text { (degeneracy) }\end{array}$ & $\begin{array}{l}\text { Chr: Pos. (hg17) } \\
\text { and orientation }\end{array}$ & & $\begin{array}{l}\text { Duplicon } \\
\text { length }\end{array}$ & $\begin{array}{l}\text { Characterized genes and } \\
\text { pseudogenes in duplicons }\end{array}$ \\
\hline \multirow[t]{2}{*}{$C D$} & rs11060028 & 12: & $128 \mathrm{M} \rightarrow$ & $1.5 \mathrm{~kb}$ & GLT1D1 \\
\hline & $93.4 \%(P)$ & 10: & $102 \mathrm{M} \leftarrow$ & $1.2 \mathrm{~kb}$ & {$[\mathrm{ABCC} 2]$} \\
\hline \multirow[t]{2}{*}{$\mathrm{T} 1 \mathrm{D}$} & rs3805006 & 3: & $4,775 \mathrm{~K} \rightarrow$ & 402 & ITPR1, [EGO] \\
\hline & $93.4 \%(P)$ & 3: & $4,773 \mathrm{~K} \leftarrow$ & 407 & ITPR1, [EGO] \\
\hline \multirow[t]{2}{*}{$\mathrm{BD}, \mathrm{HT}$} & rs9378249 & 6: & $31.4 \mathrm{M} \rightarrow$ & $27 \mathrm{~kb}$ & HLA-B, DHFRP2 \\
\hline & $92.9 \%(F)$ & $6:$ & $31.3 \mathrm{M} \rightarrow$ & $35 \mathrm{~kb}$ & $\mathrm{HLA}-\mathrm{C}$ \\
\hline \multirow[t]{2}{*}{ HT } & rs841245 & 12: & $27.1 \mathrm{M} \rightarrow$ & $84 \mathrm{~kb}$ & - \\
\hline & $92.0 \%(P)$ & 12: & $27.6 \mathrm{M} \rightarrow$ & $82 \mathrm{~kb}$ & PPFIBP1 \\
\hline \multirow[t]{4}{*}{$\mathrm{BD}$} & rs12070036 & 1: & $224 \mathrm{M} \rightarrow$ & $9 \mathrm{~kb}$ & ZNF678 \\
\hline & $91.9 \%$ & 12: & $7 \mathrm{M} \leftarrow$ & $3.5 \mathrm{~kb}$ & [PEX5] \\
\hline & $91.1 \%$ & 12: & $123 \mathrm{M} \leftarrow$ & $10 \mathrm{~kb}$ & [RILPL1], [TMED2] \\
\hline & $90.9 \%$ & 11: & $26 \mathrm{M} \leftarrow$ & $2.7 \mathrm{~kb}$ & - \\
\hline \multirow[t]{2}{*}{ RA } & rs4988327 & 11: & $68 \mathrm{M} \rightarrow$ & $104 \mathrm{~kb}$ & LRP5 \\
\hline & $91.2 \%$ & $22:$ & $24 \mathrm{M} \leftarrow$ & $64 \mathrm{~kb}$ & LRP5L \\
\hline \multirow[t]{3}{*}{$\mathrm{T} 2 \mathrm{D}$} & rs11010908 & 10: & $37.2 \mathrm{M} \rightarrow$ & $6 \mathrm{~kb}$ & - \\
\hline & $90.6 \%$ & 10: & $27.2 \mathrm{M} \leftarrow$ & $12 \mathrm{~kb}$ & - \\
\hline & $90.0 \%$ & 10: & $27.6 \mathrm{M} \rightarrow$ & $6 \mathrm{~kb}$ & - \\
\hline \multirow[t]{7}{*}{$C A D$} & rs295470 & 3: & $141 \mathrm{M} \rightarrow$ & $1.9 \mathrm{~kb}$ & ACTGP1, [RBP2] \\
\hline & $89.5 \%$ & 17: & $77 \mathrm{M} \leftarrow$ & $2.3 \mathrm{~kb}$ & ACTG1, [FSCN2] \\
\hline & $89.1 \%$ & 1: & $92 \mathrm{M} \leftarrow$ & 866 & - \\
\hline & $87.8 \%$ & $x:$ & $53 \mathrm{M} \leftarrow$ & 636 & - \\
\hline & $86.6 \%$ & $2:$ & $108 \mathrm{M} \rightarrow$ & 568 & - \\
\hline & $86.5 \%$ & 17: & $17 \mathrm{M} \rightarrow$ & 696 & {$[\mathrm{FLCN}]$} \\
\hline & $85.9 \%$ & 3: & $12 \mathrm{M} \rightarrow$ & $1.9 \mathrm{~kb}$ & SYN2 \\
\hline \multirow[t]{7}{*}{$\mathrm{BD}, \mathrm{HT}$} & rs2122231 & 3: & $35 \mathrm{M} \rightarrow$ & $4.9 \mathrm{~kb}$ & - \\
\hline & $88.8 \%$ & 6: & $117.0 \mathrm{M} \rightarrow$ & $4 \mathrm{~kb}$ & [NT5DC1] \\
\hline & $88.6 \%$ & 18: & $5 \mathrm{M} \rightarrow$ & $3.9 \mathrm{~kb}$ & - \\
\hline & $88.5 \%$ & $2:$ & $194 \mathrm{M} \rightarrow$ & $1 \mathrm{~kb}$ & - \\
\hline & $87.9 \%$ & 1: & $96 \mathrm{M} \rightarrow$ & $4.9 \mathrm{~kb}$ & - \\
\hline & $87.3 \%$ & 10: & $117 \mathrm{M} \rightarrow$ & $4.2 \mathrm{~kb}$ & - \\
\hline & $86.3 \%$ & 20: & $24 \mathrm{M} \rightarrow$ & 728 & - \\
\hline \multirow[t]{2}{*}{$\mathrm{BD}, \mathrm{HT}$} & SNP_A-1948953 & 17: & $17 \mathrm{M} \rightarrow$ & 894 & LNX1 pseudogene LOC644909 \\
\hline & $87.0 \%(P)$ & 4: & $54 \mathrm{M} \leftarrow$ & $21 \mathrm{~kb}$ & LNX1 \\
\hline \multirow[t]{2}{*}{$C D$} & rs9839841 & 3: & $16 \mathrm{M} \rightarrow$ & $110 \mathrm{~kb}$ & RFTN1 \\
\hline & $86.8 \%(F)$ & Y: & $7.6 \mathrm{M} \rightarrow$ & $100 \mathrm{~kb}$ & RFTN1-pseudogene LOC360015, [TTY12], [TTTY16] \\
\hline \multirow[t]{3}{*}{$B D, T 2 D$} & rs4850057 & 2: & $4 \mathrm{M} \rightarrow$ & $4.7 \mathrm{~kb}$ & - \\
\hline & $86.8 \%$ & 9: & $35 \mathrm{M} \rightarrow$ & $4.5 \mathrm{~kb}$ & UNC13B \\
\hline & $86.1 \%$ & 11: & $5 \mathrm{M} \rightarrow$ & $3.0 \mathrm{~kb}$ & [TRIM68], [OR51D1], [OR51E1] \\
\hline
\end{tabular}


Table 4 SNPs identified in the MHC region for T1D using the stringent filter

\begin{tabular}{|c|c|c|c|c|c|}
\hline Cohort(s) & $\begin{array}{l}\text { SNP/identity } \\
\text { (degeneracy) }\end{array}$ & $\begin{array}{l}\text { Chr: Pos. (hg17) } \\
\text { and orientation }\end{array}$ & & $\begin{array}{l}\text { Duplicon } \\
\text { length }\end{array}$ & $\begin{array}{l}\text { Characterized genes and } \\
\text { pseudogenes in duplicons }\end{array}$ \\
\hline \multirow[t]{2}{*}{$\overline{\mathrm{T} 1 \mathrm{D}}$} & rs9378249 & 6: & $31.4 \mathrm{M} \rightarrow$ & $27 \mathrm{~kb}$ & HLA-B, DHFRP2 \\
\hline & $92.9 \%(F)$ & 6: & $31.3 \mathrm{M} \rightarrow$ & $35 \mathrm{~kb}$ & HLA-C \\
\hline \multirow[t]{2}{*}{ T1D } & rs9257223 & 6: & $29 \mathrm{M} \rightarrow$ & $16 \mathrm{~kb}$ & - \\
\hline & $92.5 \%$ & 11: & $50 \mathrm{M} \rightarrow$ & $16 \mathrm{~kb}$ & - \\
\hline \multirow[t]{5}{*}{$\mathrm{T} 1 \mathrm{D}$} & rs389600 & 6: & $30 \mathrm{M} \rightarrow$ & $4 \mathrm{~kb}$ & HLA-K \\
\hline & $87.5 \%$ & 6: & $30 \mathrm{M} \leftarrow$ & $4 \mathrm{~kb}$ & $\mathrm{HLA}-\mathrm{A}$ \\
\hline & $87.5 \%$ & 6: & $30 \mathrm{M} \leftarrow$ & $4 \mathrm{~kb}$ & $\mathrm{HLA}-\mathrm{H}$ \\
\hline & $86.2 \%$ & 6: & $30 \mathrm{M} \leftarrow$ & $4 \mathrm{~kb}$ & HLA-J \\
\hline & $85.8 \%$ & 6: & $30 \mathrm{M} \leftarrow$ & $3.5 \mathrm{~kb}$ & HLA-G \\
\hline
\end{tabular}

rs10502407 in T2D (6), CAD (6)

CIDEA has known associations to obesity, insulin resistance, and T2D [47-49], which are also risk factors for CAD [50]. The duplicon is located upstream of CIDEA in a potential enhancer locus.

rs12134625 in CAD (3)

The FUSIP1 gene specifically represses splicing during mitosis [51,52] and in cells subject to heat shock [53]. Cells lacking FUSIP1 are defective in recovery after heat shock [53]. Splice repression after heat shock prevents the possible accumulation of inaccurately spliced mRNAs, until the heat-damaged splicing apparatus is restored to normal [53]. FUSIP1-null mice display multiple cardiac defects during embryonic development, due to improper processing of pre-mRNA encoding cardiac triadin [54]. Somatic defects in FUSIP1 that lead to misspliced triadin transcripts could be a pathogenic mechanism in CAD.

rs9551988 in CAD (3), BD (3), HT (3)

PSPC1 has sequence-specific RNA-binding domains, and localizes to paraspeckles [55]. While the function of

Table 5 Numeric codes describing the strength of evidence for an association of a gene with a disease

\begin{tabular}{ll}
\hline Code & Kind of evidence \\
\hline 6 & $\begin{array}{l}\text { Known association of the gene with the disease. } \\
\text { Gene is known to interact with an intermediate, and the }\end{array}$ \\
$\begin{array}{l}\text { intermediate has a known association with the disease. } \\
\text { Known association of the gene with a function central to } \\
\text { disease pathogenesis (for example, insulin secretion for } \\
\text { diabetes). } \\
3\end{array}$ & $\begin{array}{l}\text { Gene is known to interact with an intermediate, and the } \\
\text { intermediate has a known association with a function central to } \\
\text { disease pathogenesis. }\end{array}$ \\
$\begin{array}{l}\text { Known association of a region containing the gene with the } \\
\text { disease. } \\
0\end{array}$ & $\begin{array}{l}\text { Gene disruption is known to have a general mutagenic effect. } \\
\text { No evidence. }\end{array}$ \\
\hline
\end{tabular}

paraspeckles is not fully understood, Prasanth et al. [56] describe how paraspeckles store CTN-RNA, which is cleaved under conditions of stress and released for immediate translation into protein. Prasanth et al. argue that this mechanism allows the cell to provide a rapid stress response, rather than having to wait for RNA transcription [56]. The released mRNA encodes SLC7A2, also known as CAT2, a cationic amino acid transporter involved in L-arginine transport, a necessary step in nitric oxide (NO) synthesis [56,57]. Insulin directly effects vascular endothelium and smooth muscle via nitric oxide release $[58,59]$. The pathway for insulininduced NO synthesis involves L-arginine transport and the SLC7A2 gene $[58,60,61]$. The physiological implications of a dysregulation of insulin in obesity, CAD, and HT are well known [58,59]. A dysregulation of SLC7A2 function could have similar effects. In preeclampsia (HT and proteinuria in pregnancy) the L-arginine NO system of circulating leukocytes appears dysregulated [62]. The $\mathrm{L}$-arginine NO pathway appears to be involved in the pathogenesis of $\mathrm{BD}[63,64]$.

\section{rs935019 in HT (4)}

The two duplicons are immediately adjacent and aligned within the GYPC gene. Such an arrangement provides an opportunity for improper recombination due to misalignment. Indeed, deletion variants of the GYPC gene have been attributed to unequal crossover at these duplicons [65]. One of these deletions frequently occurs spontaneously in E. coli during cloning [65], suggesting that spontaneous somatic deletions are also likely.

The GYPC gene codes for the GPC and GPD proteins, which regulate the shape and mechanical properties of red blood cells [66]. While there is no direct evidence linking GYPC to HT, the tissue-specificity and function of GYPC make such a link plausible.

rs12227938 in HT (3)

The HERG gene encodes pore-forming alpha-subunit protein important for repolarizing $\mathrm{K}^{+}$current in the 
heart [67]. The ALG10B gene (also known as KCR1) modulates HERG, reducing the sensitivity of cardiac cells to arrhythmic disturbance [68,69]. ALG10B suppresses heart rhythm and regulates cardiac automaticity [70]. Polymorphisms on ALG10B are associated with the risk of acquired long QT syndrome, a cardiac rhythm disturbance [71]. Somatic defects in ALG10B would have direct relevance to $\mathrm{HT}$.

SNP A-1797773 in T2D (4)

VPS35 is part of the retromer protein complex, which has a variety of sorting-related functions [72]. Mutant VPS35 is associated with improper insulin secretion [73].

\section{rs 12381130 in $T 1 D(0)$}

This particular duplicon has homology with many other regions. Interestingly, on chromosomes $3,4,8$, and 11 there are pairs of homologous duplicons about $4 \mathrm{Mb}$ apart. Gene conversion at rs 12381130 could be a marker of more general conversion and/or improper recombination at these locations, potentially leading to somatic deletions, duplications or inversions of the sequence between duplicon pairs on a chromosome.

\section{rs11060028 in CD (6)}

GLT1D1 appears to be a glycosyltransferase, but relatively little is known about its specific function. The chromosome 10 duplicon is $16 \mathrm{~kb}$ upstream of $\mathrm{ABCC} 2$ in a possible enhancer locus. ABCC2 is expressed on the apical membrane in the jejunum, ileum and colon [74]. It is an efflux transporter, responsible for extruding toxic substances from the cell $[29,74]$. ABCC2 expression is reduced in $C D$, in both the ileum and colon [29]. rs3805006 in T1D (4)

rs3805006 is located within an intron of ITPR1, and 7 $\mathrm{kb}$ upstream of the noncoding RNA gene EGO [75]. ITPR1, together with the related receptors ITPR2 and ITPR3, regulate calcium release within the insulin secretion pathway in pancreatic beta cells [76]. The ITPR3 gene was associated with T1D in a Swedish population [77], although see [78,79].

\section{rs9378249 in $B D(0)$ and $H T(0)$}

This SNP falls within the MHC region on chromosome 6. There is no general association of the MHC region with either BD or HT in the WTCCC data [11], although the region has recently been implicated in schizophrenia [80].

In the cluster plots for rs9378249, the no-calls for BD, $\mathrm{HT}$, and T1D are located in the middle of the heterozygote cluster. This kind of clustering pattern strongly suggests variation between populations in the magnitude of the intensity measurements. Intensity variations could be a result of either somatic gene conversion or somatic deletion in certain populations, assuming in both cases that the control populations have higher intensity than the affected populations.
A diagram of the homology between the two duplicons is given in Figure 4. From this diagram, it becomes apparent that conversion of the lower region by the upper region could eliminate the DHFRP2 sequence entirely.

Relatively low raw intensity levels at a locus would be expected if there were a significant number of deletions at that locus in somatic cells. Low intensity at rs7761068, which resides in the putatively deleted region and is the closest SNP to DHFRP2 in the microarray data set, could be interpreted as an indicator of more frequent somatic deletion of the region containing DHFRP2.

To determine a threshold for low/high intensity at rs7761068, the two control populations were pooled and the three genotype clusters were analyzed separately. For the first homozygous cluster, which is close to the $y$-axis in the cluster plot, the median y-intensity is 1.227. For the second homozygous cluster, which is close to the $x$-axis in the cluster plot, the median $\mathrm{x}$-intensity is 1.493 . For the heterozygous cluster, the median $(x+y)$-intensity is 1.888 . Based on these numbers, an individual is defined to have low intensity at rs7761068 if the $x, y$, and $x+y$ values are all lower than the corresponding thresholds; otherwise the individual is said to have high intensity at rs7761068. Each of the populations was then partitioned into low and high intensity fractions.

The results shown in Figure 5 strongly suggest that there is increased deletion in all disease populations besides RA. (A $2 \times 2$ chi-squared test comparing each population with the combined controls yields $P=0.02$ for $\mathrm{CD}$, and $P<10^{-13}$ for the other five populations.) rs9378249 displays an intensity distribution with features similar to rs7761068 shown in Figure 5, suggesting that deletion due to conversion and/or deletion of the green regions is more likely to be responsible than interactions between the pink region containing DHFRP2 and the region containing DHFR.

DHFRP2 is a pseudogene with homology to DHFR. DHFR codes for dihydrofolate reductase, an enzyme required for the synthesis of thymine nucleotides. Impaired $\mathrm{T}$ synthesis causes misincorporation of uracil into DNA, leading to various kinds of DNA damage [81]. While DHFRP2 is noncoding, its mRNA could interact with DHFR mRNA via an antisense regulatory mechanism [82]. The DHFR gene locus shows evidence of both sense and antisense transcription [83], consistent with a role for antisense regulation. (Since interactions of DHFRP2 and DHFR have not been demonstrated, the evidence level of this hypothesis is zero.)

In $\mathrm{BD}$ patients, folate sensitive fragile sites are expressed more often than in controls [84]. Polymorphisms in the MTHFD1 gene, which encodes several folate 

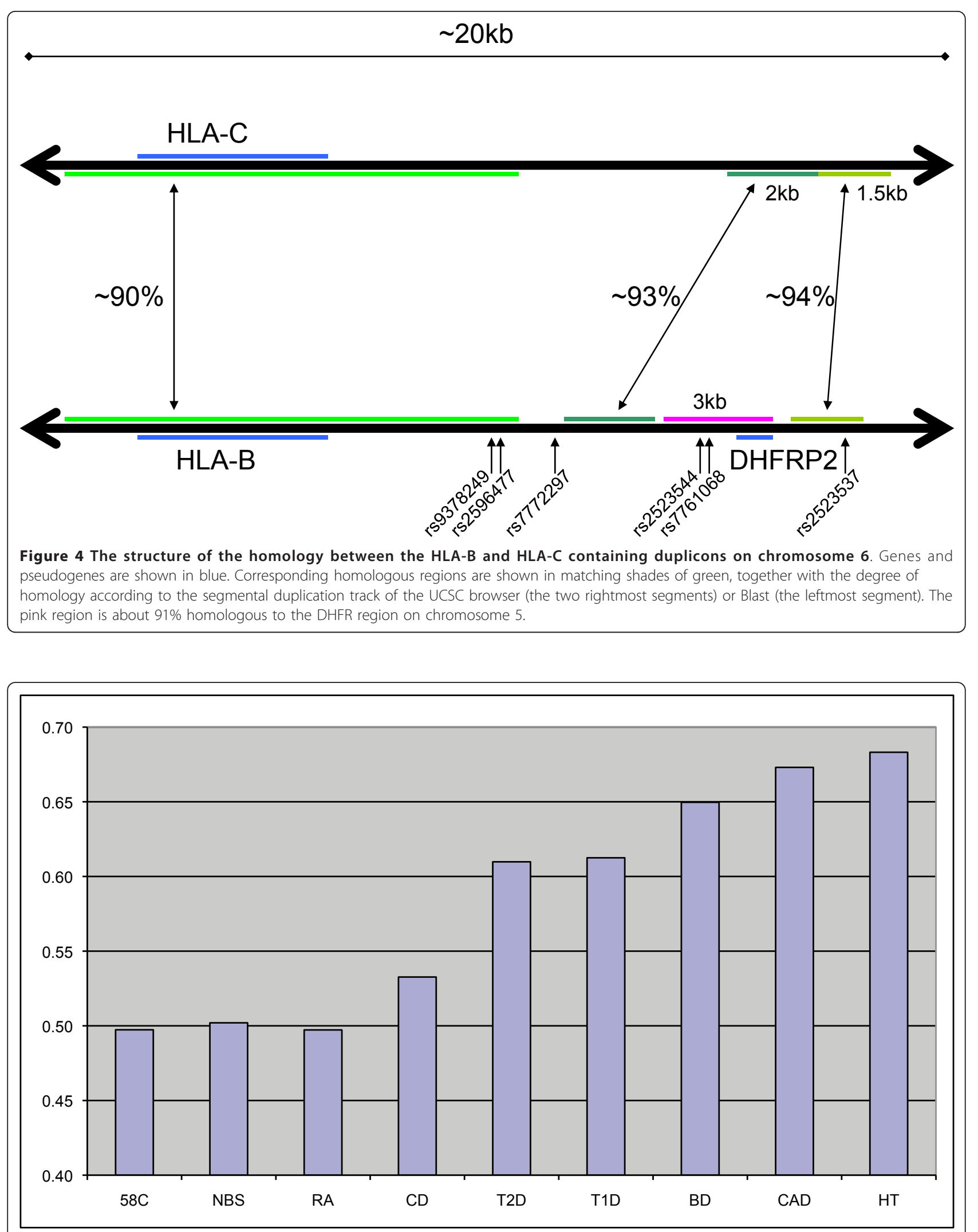

Figure 5 Proportion of each of the nine populations having low measured intensity at rs7761068. The intensity thresholds were chosen so that $50 \%$ of the combined control population would have low intensity. 
enzymes, are associated with BD [85]. Polymorphisms in the MTHFR gene, which encodes 5,10-methylenetetrahydrofolate reductase, have been associated with HT [86] and BD [87]. High homocysteine levels, which are often associated with folate deficiency, are associated with hypertension [88], and folate supplementation appears to decrease the risk of developing HT [89].

rs841245 in HT (5)

PPFIBP1 encodes the liprin-beta-1 gene, which is highly expressed in the heart [90]. Liprin-beta-1 interacts specifically with the S100A4/Mts1 protein in vivo [91]. The S100A4/Mts1 protein is more highly expressed in individuals with HT, and appears to cause changes in vasculature [92-95].

rs12070036 in BD (5)

ZNF678 has unknown function. It has diverged significantly from all other known zinc-finger proteins [96], and is associated with human variation in height [97].

The chromosome 12 duplicon at $7.2 \mathrm{Mb}$ is located $3.3 \mathrm{~kb}$ upstream of PEX5 in a potential promoter region. PEX5 is a gene responsible for recognizing PTS proteins in the peroxisome [98]. Defects in PEX5 cause one of several peroxisome biogenesis disorders, accompanied by reduced plasmalogen biosynthesis in the brain $[99,100]$. Plasmalogen is a lipid that is abundant in myelin, and peroxisome dysfunction leads to demyelination and axon degeneration in the central nervous system [101]. Somatic mutations in a PEX5 promoter could lead to situations in which some neurons are myelin-deficient, causing aberrant signaling. Demyelination has been previously suggested as a pathogenic mechanism in BD [102], and an association between $\mathrm{BD}$ and multiple sclerosis (a demyelinating disease) have been observed [103,104]. Valproate treatment for $\mathrm{BD}$ appears to change the behavior of the peroxisome in neurons [105].

\section{rs4988327 in RA (6)}

The scatter plot for this SNP is shown in Figure 3.

LRP5 is a member of the canonical WNT5a signaling pathway that is initiated by IL6 in rheumatoid synovial fibroblasts [106]. LRP5 is also associated with bone mineral density and with susceptibility to osteoarthritis $[107,108]$.

rs 11010908 in T2D (0)

While there are no characterized genes in the duplicons, two of the duplicons are adjacent, spanning a $370 \mathrm{~kb}$ region that includes the genes ANKRD26, YME1L1, MASTL, and ACBD5. ANKRD26-knockout mice develop hyperphagia-induced obesity and insulin resistance [109], as might be expected for a gene associated with T2D.

\section{rs295470 in CAD (5)}

The function of ACTG1 appears to be the maintenance of the actin cytoskeleton [110]. A muscle-specific
ACTG1-knockout leads to progressive myopathy [111]. Conversely, injection of a human ACTG1 construct (but not constructs based on ACTC1 or ACTG2) into adult rat cardiomyocytes caused a cessation of beating, suggesting a dominant negative effect of overexpression of ACTG1 [112]. ACTG1 appears to play an important role in the structure and normal function of striated muscle [111,113].

RBP2 cDNA is down-regulated by low density lipoprotein, which may be relevant to CAD [114]. RBP2 participates in the uptake and/or metabolism of vitamin A, which is converted to retinol. Low plasma retinol is associated with coronary events [115].

\section{rs 2122231 in $B D(0)$ and $H T(0)$}

rs2122231 is located within a region of human ERV9 retroviral sequence. Gene conversion between this sequence and other ERV9 sequence could change ERV9 expression behavior. Variation in ERV9 expression has been associated with psychiatric disorders, including BD and schizophrenia [116,117].

ERV9 long terminal repeat (LTR) sequence also appears in the promoter of the beta globin gene [118]. Disruptions of ERV9 expression could affect beta globin transcription, providing a plausible link to HT. There are many ERV9 LTR sequences in the human genome; in the absence of evidence that this particular region is responsible for ERV9 expression, the evidence level for these associations is 0 .

\section{SNP_A-1948953 in HT (3) and BD (3)}

LNX proteins including LNX1 interact with members of the Notch signaling pathway that could affect the formation of neuronal cell shape and synaptic connections in the brain [119]. LNX1 interacts with CAST in neurons, and CAST is associated with neurotransmitter release [120]. These properties of LNX1 may be relevant for $\mathrm{BD}$.

LNX1 binds with CXADR, the coxsackievirus and adenovirus receptor [121]. Coxsackievirus seroprevalence has been associated with HT [122].

Interestingly, LNX1 RNA is a much closer match to the SNP_A-1948953 duplicon than the LNX1 DNA; there are gaps in homology that coincide with the LNX1 introns.

\section{rs9839841 in CD (4)}

The duplicon for this SNP is on the Y-chromosome, suggesting that gene conversion should be observed only in males. The rs9839841 SNP is a C/T polymorphism on chromosome 3 . The corresponding Y-chromosome locus has a 35 bp flanking sequence that is identical to the chromosome 3 sequence containing the $\mathrm{T}$ allele. As a result, the microarray will show a base intensity for the $T$ allele that is higher in males than in females. One should thus interpret the scatter plots and clustering results with caution, as they may be influenced by the relative 
frequency of each gender in the population. In support of a true CD association at this locus for males, Figure 6 shows a scatter plot limited to males for the CD, 58C and NBS populations. The CD population shows a higher spread despite having approximately the same number of data points as each control population.

RFTN1 modulates T-cell signals, particularly $\mathrm{Th}_{17}$, and influences the severity of autoimmune responses [123]. RFTN1 is also needed for B-cell receptor signal transduction [124]. CD and some other chronic inflammatory diseases are mediated by $\mathrm{Th}_{17}$ cells $[125,126]$.

rs4850057 in T2D (6) and $B D$ (4)

UNC13B expression is reduced in pancreatic beta cells of rat models of T2D [127]. Conversely, overexpression of UNC13B amplifies insulin exocytosis [127]. These results are directly relevant to $\mathrm{T} 2 \mathrm{D}$ in which insulin exocytosis is dysregulated [128,129].

UNC13B also modulates neurotransmitter release in neurons [130-132], a pathway relevant for BD.

\section{The $H L A$ region in T1D}

It is difficult to separate a conversion signal from the broader association signal for T1D in the MHC region; the $\mathrm{MHC}$ region on chromosome 6 has extensive association with T1D [11]. Recent high resolution studies have identified an association signal at the HLA-B locus (but not the HLA-C locus) that is independent of the MHC class-II loci [79]. HLA-C has been linked with T1D when considered in combination with KIR genes that are expressed in natural killer cells $[133,134]$.

There are many plausible ways that disruption of an immunity-related gene could modulate T1D pathogenesis. Gene conversion provides additional candidate hypotheses. For example, gene conversion in the duplicons associated with rs389600 could lead to disruption of HLA-G expression. HLA-G expression is immunoprotective in pancreatic islets [135]. An association between the HLA-G region and T1D has previously been observed [136].

\section{Significance of stringent test associations}

The ways that the identified genes appear to be relevant to the corresponding disease are diverse. This diversity makes it difficult to formally quantify the significance of the noted associations. In particular, it might be that any sample of genes from duplicated regions leads to many associations with disease pathways if the literature is examined to sufficient depth. To eliminate this possibility, and to quantify the degree of 'background' association one would expect, I conducted a mock association study.

In the mock study, I identified ten SNPs for each disease. The SNPs were chosen to reside on known segmental duplications from the segmental duplication database. A chi-squared statistic comparing the distributions of $\mathrm{AA} / \mathrm{AB} / \mathrm{BB}$ genotypes in controls and in the disease samples was computed, and the ten SNPs that minimized this statistic were chosen. (The selected SNPs for a disease sample are therefore those whose genotype distributions are closest to the controls.) For each disease I searched for disease associations using the literature in the same way that associations were sought for SNPs selected by the various filters. The details are presented in Tables S15 and S16 in Additional file 1.

The hypothesis being tested is that the associations of the stringent test and the mock test differ in the degree of association to the corresponding disease. The rate at which known evidence was found in the stringent test and the mock study is summarized in Table 6. SNPs in the MHC region for T1D were excluded. A Fisher's exact test of the difference between the stringent filter and mock study at evidence level three gives $P<10^{-9}$. Even if one limits the stringent test results to SNPs

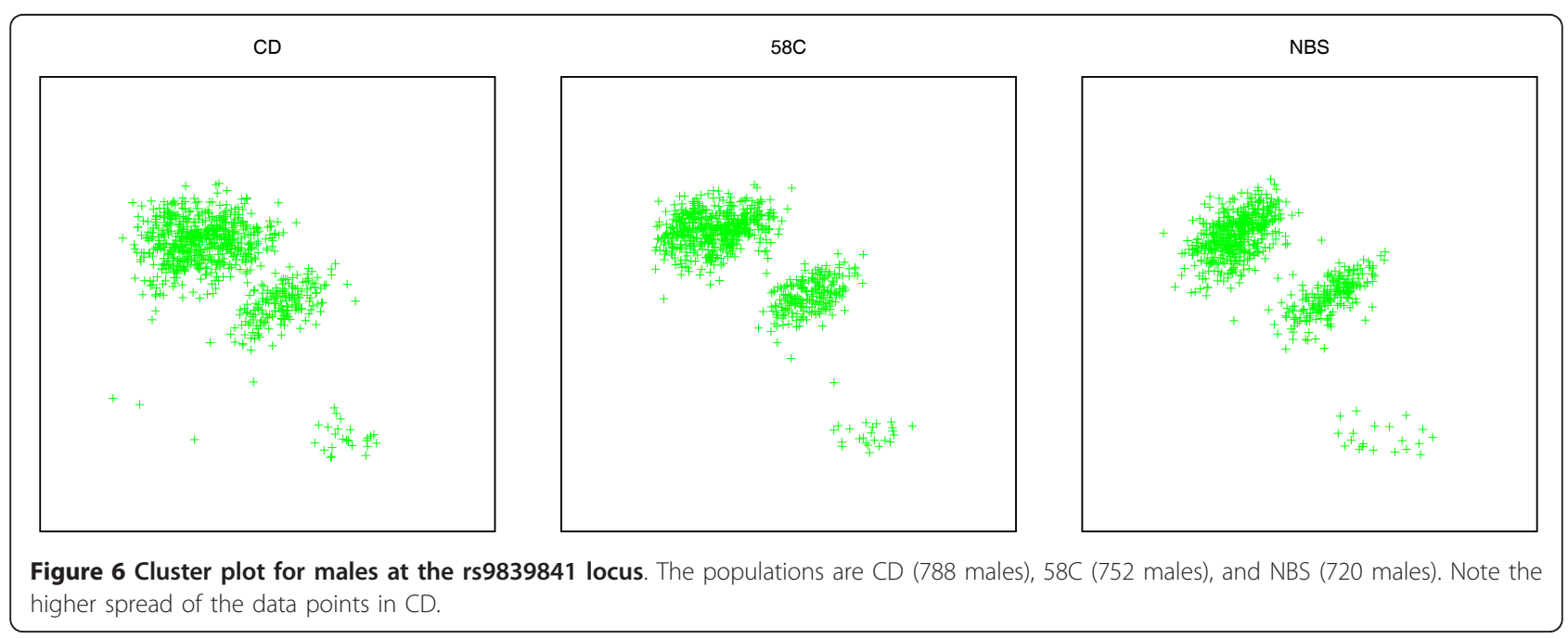


belonging to duplicons in the segmental duplication database, a Fisher's exact test at evidence level three gives $P<10^{-8}$. There are consistent disease associations for 22 of the 28 identified instances, and one can reject the null hypothesis that the observed associations are random.

\section{A permutation test}

Another way to assess the significance of the stringent test associations is via a permutation test. By switching the labels of cases and controls with probability 0.5 and applying the stringent test conditions, one can test the null hypothesis that the distribution among cases relative to controls is the same as the distribution of controls relative to cases.

In order to perform this test without manually checking for homology, I limit the analysis to associations in regions of at least $90 \%$ homology identified by the segmental duplication database. SNPs in the MHC region for T1D are excluded. With those limitations, there are $16 \mathrm{SNP} /$ disease pairs satisfying the original stringent test. Switching the labels of cases and controls for each disease and SNP yields five qualifying SNP/disease pairs.

Based on this information, it is possible to approximate the permutation test distribution as a binomial distribution with $N=21$ and a probability of 0.5 . The probability $p$ that one would observe at least 16 associations under such a distribution is 0.013 , allowing us to reject the null hypothesis.

\section{The relaxed filter}

Seventeen stringent-filter SNPs with homology sufficient to satisfy the segmental duplication database constraints are also returned by the relaxed filter. 65 additional instances covering 50 distinct SNPs survive the relaxed filter. Four of these SNPs are among those identified (for other diseases) using the stringent filters. Four additional SNPs are distinct from those identified by the stringent test, but reside in the same duplicons as SNPs from the stringent test. This data is summarized in Table 7. $P$ values for these associations are given in Tables S2 and S3 in Additional file 1.

By design, the gene associations identified solely by the relaxed filter may include false positives. Nevertheless, several of these associations appear to be plausible for the disease(s), and are promising candidates for further study.

The region containing rs10502407 in chromosome 18 has known associations with bipolar disorder. GNAL, and possibly other genes in this region, are subject to epigenetic regulation, and constitute potential susceptibility genes for BD and schizophrenia [137].

rs3858741 is identified as a gene conversion locus for BD, CD and HT and rs9551988 is associated with T2D. These two SNPs are within the same duplicon. The discussion of rs 9551988 for the stringent filter analysis covers the $\mathrm{BD}, \mathrm{HT}$, and T2D associations. The NO pathway also appears to be important for CD [138,139].

ALG10B is associated with HT in the stringent filter. The association with CAD in the relaxed filter can also be attributed to elongated QT intervals, as can the association with T1D [140]. ALG10B also appears to modulate $\mathrm{K}^{+}$current in neurons [141], making the link to BD plausible. rs11053044 is identified as a gene conversion locus in T2D; rs11053044 falls within the ALG10 duplicon. Elongated QT intervals are also observed in T2D [142]. Variants of the pore-forming alpha-subunit potassium channel gene KCNQ1 are associated with reduced insulin secretion and T2D [143], and with forms of the long QT-syndrome [143]. VPS35 is associated with BD and CD. VPS35 appears to regulate Wnt signaling [144]. Wnt signaling is important for the proper structure of the absorptive epithelium of the small intestine [145], a plausible link with $\mathrm{CD}$. The Wnt pathway is also associated with BD [146].

The SNP rs9624808 is identified in T1D by the relaxed test; rs9624808 is in same duplicon as rs4988327. LRP5 has been identified as a susceptibility locus for T1D $[147,148]$.

The SNP rs1291361 associates HTR7 and HEBP1 with BD. HTR7 is a serotonin receptor that mediates impulsive behavior [149], and appears to have variants associated with schizophrenia [150]. HEBP1 appears to function in the brain's response to oxidative stress [151].

PARP4, associated with T2D, is a DNA repair molecule involved in nick sensing [152].

ROCK2, associated with CAD, HT, RA, and T1D, is involved in various functions including actin cytoskeleton

Table 6 Comparison of the stringent and mock tests

\begin{tabular}{|c|c|c|c|c|c|c|c|c|}
\hline \multirow[b]{2}{*}{ Test } & & \multicolumn{7}{|c|}{ Strength of evidence } \\
\hline & & 6 & $\geq 5$ & $\geq 4$ & $\geq 3$ & $\geq 2$ & $\geq 1$ & 0 \\
\hline Mock & $(/ 70)$ & $6(4)$ & $6(4)$ & $7(5)$ & $11(8)$ & $13(9)$ & $16(11)$ & $84(59)$ \\
\hline \multirow[t]{2}{*}{ Stringent } & (/28) & $21(6)$ & $36(10)$ & $54(15)$ & $79(22)$ & $79(22)$ & $79(22)$ & $21(6)$ \\
\hline & $(/ 16)$ & $31(5)$ & $50(8)$ & $62.5(10)$ & 87.5 (14) & $87.5(14)$ & $87.5(14)$ & $12.5(2)$ \\
\hline
\end{tabular}

Percentage (count) of SNPs with evidence in the various categories for the mock and stringent tests. The second row for the stringent test limits the analysis to SNPs belonging to a duplicon in the segmental duplication database. 
Table 7 Additional SNPs identified using the relaxed filter

\begin{tabular}{|c|c|c|}
\hline SNP & Disease(s) & Characterized genes in duplicons \\
\hline rs10147986 & $C D$ & (40 duplicons) \\
\hline rs10502407 & $\mathrm{BD}$ & [CIDEA] \\
\hline rs10896468 & $C A D$ & OR8U8, OR5M8 \\
\hline rs11010995 & RA & - \\
\hline rs11028186 & RA & $\begin{array}{l}\text { ALG1L, ASNS, [ZNF195], [FAM86B2], } \\
\text { [DEFB10P1], [DEFA5], [ZFYVE20] }\end{array}$ \\
\hline rs11053044 & $\mathrm{T} 2 \mathrm{D}$ & ALG10, ALG10B \\
\hline rs11118278 & CAD & CR1L, MCP \\
\hline rs1192923 & HT & [ORAOV1] \\
\hline rs12227938 & $\begin{array}{l}\mathrm{BD}, \mathrm{CAD} \\
\mathrm{T} 1 \mathrm{D}\end{array}$ & ALG10, ALG10B \\
\hline rs12256867 & $\mathrm{T} 2 \mathrm{D}$ & ZNF33A, ZNF37A, ZNF33B, ZNF37B, [ZNF25] \\
\hline rs12413153 & CAD & DDX18, BTBD15, WDR22, [IBRDC2] \\
\hline rs1291361 & $\mathrm{BD}$ & HTR7, HTR7P, [HEBP1] \\
\hline rs1404223 & CAD & - \\
\hline rs17080801 & $\mathrm{T} 2 \mathrm{D}$ & PARP4, TPTE2 \\
\hline rs17230081 & $\mathrm{T} 2 \mathrm{D}$ & ORM1, ORM2 \\
\hline rs17636964 & $C D$ & IPMK \\
\hline rs17645907 & $\mathrm{T} 2 \mathrm{D}$ & [POMZP3] \\
\hline rs1842055 & $C A D$ & - \\
\hline rs1868584 & $\begin{array}{l}C A D, H T \\
\text { RA, T1D }\end{array}$ & ROCK2, CGGBP1, [ZNF654] \\
\hline rs2120273 & $\mathrm{BD}$ & - \\
\hline rs2236014 & $\mathrm{BD}$ & MTRF1L, [FBX05] \\
\hline rs2515832 & RA & $\begin{array}{l}\text { MAGEA12, CSAG1, MAGEA2, MAGEA3, TRAG3, } \\
\text { [MAGEA6] }\end{array}$ \\
\hline rs2523544 & T1D & $\begin{array}{l}\text { DHFRP2, DHFRL1, DHFR, PSMA8, [HLA-B], } \\
\text { [MSH3], [NSUN3] }\end{array}$ \\
\hline rs2617729 & $C D, T 2 D$ & ZNF761, ZNF765, ZNF813, [ZNF331] \\
\hline rs330201 & $C A D$ & MRPL10, [LRRC46], [OSBPL7] \\
\hline rs3858741 & $\mathrm{BD}, \mathrm{CD}, \mathrm{HT}$ & PSPC1, [TUBA3C] \\
\hline rs4318932 & $C D$ & TYW1, TYW1B, [STAG3L4] \\
\hline rs4453734 & $C A D, R A$ & - \\
\hline rs4473816 & RA & [GSPT2] \\
\hline rs4532803 & $\mathrm{BD}, \mathrm{HT}$ & ELA3A, ELA3B, [HSPC157] \\
\hline rs4545817 & $\mathrm{BD}$ & ALG1, FAM86A, [COL6A4P2] \\
\hline rs4881702 & $\mathrm{BD}$ & - \\
\hline rs500192 & $\mathrm{BD}, \mathrm{T} 1 \mathrm{D}$ & TBL1XR1 \\
\hline rs5946541 & $\mathrm{BD}$ & {$[B A G E]$} \\
\hline rs6427130 & RA & $X C L 1, X C L 2$ \\
\hline rs6463213 & $B D, T 2 D$ & RBAK, RNF216L, XKR8 \\
\hline rs6744284 & $\mathrm{BD}$ & UGT1A3 -UGT1A10 \\
\hline rs6945984 & RA & CYP3A4, CYP3A7, [CYP3A5] \\
\hline rs7259082 & $C A D$ & ZNF737, M74509, ZNF66 \\
\hline rs7549545 & $\mathrm{BD}$ & [IER5] \\
\hline rs7677996 & T1D & [UGT2B7] \\
\hline rs7808342 & $\mathrm{BD}$ & - \\
\hline rs940331 & $\mathrm{T} 2 \mathrm{D}$ & [ZNF735], [ZNF716] \\
\hline rs9551988 & $\mathrm{T} 2 \mathrm{D}$ & PSPC1, [TUBA3C] \\
\hline rs9624808 & T1D & LRP5, LRP5L \\
\hline rs9665670 & $B D, C A D$ & [PDSS1] \\
\hline rs9775226 & $\mathrm{CD}, \mathrm{HT}$ & (40 duplicons) \\
\hline
\end{tabular}

Table 7 Additional SNPs identified using the relaxed filter (Continued)

\begin{tabular}{lll}
\hline SNP_A- & BD, CD & VPS35, [ORC6L] \\
1797773 & & \\
SNP_A- & CD & FAM22A \\
1817967 & & \\
SNP_A- & RA & GUSBL1, GUSBL2, SMA4, GUSBP1, [RGL4] \\
1858955 & &
\end{tabular}

Genes in square brackets are outside the duplicons, but a duplicon is at most $30 \mathrm{~kb}$ upstream of the gene. Genes for two SNPs having 40 duplicons each are omitted.

organization, and abnormal activation of the ROCK pathway has been associated with CAD and HT [153].

DHFR, associated with T1D, converts dihydrofolate into tetrahydrofolate, a necessary step for the de-novo synthesis of purines. See Figure 4 and the discussion of rs9378249, which is also associated with T1D by the stringent filter.

XCL1 and XCL2 are associated with RA. XCL1 is produced by T cells in RA [154]. XCL1 and XCL2 regulate the movement of cells expressing XCR1 [155], which is upregulated in synovial fluid in RA [156]. The UGT1A molecules, associated with $\mathrm{BD}$, are responsible for metabolizing and/or eliminating a variety of chemicals, including mutagens and toxins [157].

CYP3A4, associated with RA, is involved in vitamin D metabolism [158].

PDSS1 is associated with CAD and BD by the relaxed filter. A germ-line mutation in PDSS1 was identified in two siblings with cardiac disease and mental retardation associated with coenzyme $\mathrm{Q}_{10}$ deficiency [159].

\section{The no-call-only filter}

Seventeen stringent-filter associations meet the no-callonly filter condition on the $p$ value; see the $p_{n}$ column of Table S1 in Additional file 1. (Ten of these also satisfy the homology requirements of the no-call-only filter.) Eight relaxed-filter associations meet the nocall-only filter condition; see the $p_{n}$ column of Tables $\mathrm{S} 2$ and $\mathrm{S} 3$ in Additional file 1. Table 8 shows the remaining 50 associations covering 37 distinct SNPs. One of these SNPs (rs4471699) is among those identified (for other diseases) using the stringent filter. Nine of these SNPs are among those identified (for other diseases) using the relaxed filter. This data is summarized in Table 8.

Beyond the SNPs already identified by the relaxed filter, the following no-call-only filter associations appear to be promising candidates for future study.

SULT1A3 in BD and T2D. Impaired sulfation has been linked with various neurological diseases $[28,160]$. Sulfoconjugation of monoamines via SULT1A3 occurs within the brain, and could represent an important detoxification pathway $[28,161]$. SULT1A3 is important 
Table 8 Additional SNPs identified using the no-call-only filter

\begin{tabular}{|c|c|c|}
\hline SNP & Disease(s) & Characterized genes in duplicons \\
\hline rs10238378 & $\mathrm{BD}$ & - \\
\hline rs10485575 & $\mathrm{BD}$ & SNX5, ANO4 \\
\hline rs10768666 & RA & $\begin{array}{l}\text { HCCA2, KRTAP5-8, KRTAP5-3, [KRTAP5-2], } \\
\text { [KRTAP5-1], [KRTAP5-5], [KRTAP5-9], } \\
\text { [KRTAP5-10], }\end{array}$ \\
\hline rs10811497 & $\mathrm{BD}$ & $\begin{array}{l}\text { IFNA4, IFNA7, IFNA10, IFNA14, IFNA16, } \\
\text { IFNA17, IFNA21, [IFNW1] }\end{array}$ \\
\hline rs10896468 & $\mathrm{BD}, \mathrm{CD}, \mathrm{T} 2 \mathrm{D}$ & OR8U8, OR5M8, [OR5M3], [OR5M9] \\
\hline rs11228904 & $\mathrm{BD}, \mathrm{HT}, \mathrm{T} 1 \mathrm{D}$ & TRIM48, TRIM53 \\
\hline rs11583656 & HT & MYPT2, [UBE2T] \\
\hline rs1191684 & $\mathrm{BD}$ & [PAX8] \\
\hline rs12428824 & $\mathrm{BD}$ & $\begin{array}{l}\text { ENPP3, CTAGE4, CTAGE6, [OR2A7], } \\
\text { [OR2A2OP], [OR2A4] }\end{array}$ \\
\hline rs1421867 & $\mathrm{T} 1 \mathrm{D}$ & - \\
\hline rs1708080l & $\mathrm{BD}, \mathrm{HT}$ & PARP4, TPTE2 \\
\hline rs17310770 & $\mathrm{T} 2 \mathrm{D}$ & ROPN1, ROPN1B, CCDC14 \\
\hline rs17423694 & HT & [NBPF11] \\
\hline rs17636964 & $\mathrm{BD}, \mathrm{RA}, \mathrm{T} 2 \mathrm{D}$ & IPMK \\
\hline rs1809667 & $\mathrm{T} 1 \mathrm{D}$ & $\begin{array}{l}\text { HCCA2, KRTAP5-2, KRTAP5-8, KRTAP5-3, } \\
\text { KRTAP5-10, KRTAP5-11, KRTAP5-7, [KRTAP5- } \\
\text { 1], [DUSP8], [KRTAP5-5], [KRTAP5-9] }\end{array}$ \\
\hline rs1819829 & HT & CES7, [CES1] \\
\hline rs1820450 & RA & GPC5, [GOLGA8B] \\
\hline rs1868584 & $\mathrm{BD}$ & ROCK2, CGGBP1, [ZNF654] \\
\hline rs193017l & $\mathrm{T} 1 \mathrm{D}$ & PCDH15 \\
\hline rs2039945 & $\mathrm{T} 2 \mathrm{D}$ & - \\
\hline rs2804672 & HT & HSD17B7, HSD17B7P2, CDC10L \\
\hline rs3864439 & $\mathrm{BD}$ & $\begin{array}{l}\text { DPY19L2, DPY19L2P1, DPY19L2P4, } \\
\text { [DPY19L1], [STEAP1] }\end{array}$ \\
\hline rs4236384 & RA & SLC29A4, TNRC18 \\
\hline rs4318932 & $\mathrm{T} 2 \mathrm{D}$ & TYW1, TYW1B, [STAG3L4] \\
\hline rs4471699 & $\mathrm{BD}, \mathrm{T} 2 \mathrm{D}$ & $\begin{array}{l}\text { SULT1A3, GIYD2, BOLA2, IMAA, CORO1A, } \\
\text { MLAS, SMG1, [UQCRC2], [NPIPL3] }\end{array}$ \\
\hline rs4532803 & CAD & ELA3A, ELA3B, [HSPC157] \\
\hline rs4545817 & HT & ALG1, FAM86A, [COL6A4P2] \\
\hline rs584630 & $\mathrm{BD}$ & ZNF33A, ZNF33B, ZNF37A, ZNF37B, [ZNF25] \\
\hline rs6494831 & RA & FMN1 \\
\hline rs6510085 & RA & ZNF419, ZNF773, [ZNF772], [ZNF549] \\
\hline rs6512631 & CAD & - \\
\hline rs731999| & $\begin{array}{l}B D, C A D, H T \\
T 1 D, T 2 D\end{array}$ & CENPI \\
\hline rs8182488 & T1D & ZNF765, ZNF761, [ZNF813] \\
\hline rs9948005 & $\mathrm{BD}$ & FAM38B \\
\hline rs9976299 & RA & ITGB2 \\
\hline $\begin{array}{l}\text { SNP_A- } \\
1817967\end{array}$ & $C A D, C D$ & - \\
\hline $\begin{array}{l}\text { SNP_A- } \\
1858955\end{array}$ & $\mathrm{CD}, \mathrm{BD}$ & GUSBL1, GUSBL2, SMA4, GUSBP1, [RGL4] \\
\hline
\end{tabular}

Genes in square brackets are outside the duplicons, but a duplicon is at most $30 \mathrm{~kb}$ upstream of the gene. for the degradation of dopamine in neurons [162], and dopamine dysregulation has been linked with both BD [163] and T2D [164].

TRIM48 and TRIM53 in BD, CD, and T2D. TRIM proteins such as TRIM48 are thought to function during the cellular response to viral infection [165].

CENPI in BD, CAD, HT, T1D, and T2D. CENPI is located on the $\mathrm{X}$ chromosome, and is essential for proper segregation during mitosis [166]. Disruption of CENPI results in daughter cells having extra/missing chromosomes [166].

HCCA2 (also known as MOB2) in RA and T1D. HCCA2 appears to be important for proper segregation during mitosis $[167,168]$.

MYPT2 in HT. MYPT2 is expressed in the heart and skeletal muscle where it dephosphorylates myosin and is involved in muscle contraction $[169,170]$. Note that the matching duplicon is on the $\mathrm{Y}$ chromosome, meaning that somatic gene conversion could only happen in males.

GPC5 in RA. GPC5 expression appears to be reduced in arthritis [171] and GPC5 is located within a quantitative trait locus for arthritis [172]. A SNP within GPC5 appears to be significant for parovirus-induced arthritis [173]. Polymorphisms in GPC5 also appear to be associated with the response of multiple-sclerosis patients to interferon beta therapy [174], and GPC5 appears to be a risk factor in multiple sclerosis [175].

HSD17B7 in HT. HSD17B7 catalyzes the conversion of estrone to estradiol [176], and also is involved in cholesterol biosynthesis [177]. Estradiol treatment lowers blood pressure in hypertension [178-181]. Disruption of HSD17B7 could lower endogenous estradiol concentrations leading to an increase in blood pressure.

DPY19L2 in BD. In C. elegans, the DPY19 gene is required to properly polarize and orient migrating neuroblasts during development [182].

ITGB2 in RA. The ITGB2 gene encodes the CD18 adhesion molecule present on several kinds of immune cells. CD18 expression is upregulated in macrophages and T-cells in the peripheral blood and synovial fluid of RA patients [183,184].

\section{Cluster plot artifacts}

The 58C DNA samples were obtained from cell lines, while the other samples (including the NBS control sample) were obtained directly from blood cells [11]. Genomewide, the samples were statistically similar [11]. Nevertheless, it is conceivable that certain SNPs are systematically affected by the procedures used to establish 
cell lines. A systematic bias that reduces the no-call rate at a SNP in the $58 \mathrm{C}$ population could make other populations appear to have high no-call rates at the SNP relative to the combined controls. A significant difference between the $58 \mathrm{C}$ and NBS populations in cluster positions for a SNP could be an indicator of such a bias. At the same time, one cannot exclude the possibility that the reasons for this bias may themselves be related to gene conversion. For example, a cell that has undergone a conversion-induced mutation at a locus may not be viable as a cell-line founder, meaning that only cells with unmutated sequence at that locus will be present in the cell-line samples.

A small number of individuals in the WTCCC data generated outlying low-intensity points at multiple loci in the CAD/RA/NBS cohorts, a probable artifact of different procedures for those cohorts [11]. High no-call rates can also occur at a locus with copy number variation, where there are typically more than three clusters. I therefore visually examined all cluster plots for SNPs identified by the various filters, looking for clear examples of any of these three patterns.

The results are summarized in Table 9. For the stringent filter rows labeled with a $58 \mathrm{C}$ disparity, the no-call rate for $58 \mathrm{C}$ is less than one third of that for NBS. Four of the seven stringent filter SNPs (rs12070036, rs12381130, SNP_A-1797773, rs9257223) have significantly higher no-call rates than the NBS population alone $(P<0.005$ for a one-sided chi-squared test). The remaining three SNPs have no-call rates that are not significantly difierent from the NBS population $(P>$ $0.05)$. The $P$ value for the stringent filter comparison with the mock study remains below $10^{-8}$ at evidence level three even if all stringent filter SNPs in Table 9 are excluded.

The SNP rs7761068 was considered in Figure 5 for the analysis of rs9378249. The proportion of low-intensity individuals at rs7761068 does not segregate with the RA, CAD and NBS populations, and the 58C and NBS populations have similar intensity distributions, suggesting that the observed effect at rs7761068 is not artifactual.

Since each cohort has a different proportion of males, a duplicon on a sex chromosome could skew the cluster plot results in a population specific way. Such skew is clear for rs9839841, where a duplicon is on the Y chromosome, and where $94 \%$ of the no-calls in CD are for males. Measurements of the male proportion of no-calls for all of the other stringent filter SNPs were close to the proportions in the population as a whole (data not shown). This observation excludes the possibility that a probe sequence for these SNPs is absent from the reference human genome yet occurs frequently in the population on a sex chromosome.
Table 9 SNPs with anomalous cluster plots

\begin{tabular}{|c|c|c|c|}
\hline Filter & SNP & Disease(s) & $\begin{array}{l}\text { Cluster plot } \\
\text { feature }\end{array}$ \\
\hline Stringent, relaxed & rs10502407 & $\begin{array}{l}\text { CAD, T2D, } \\
B D\end{array}$ & $58 \mathrm{C}$ disparity \\
\hline Stringent & rs11010908 & $\mathrm{T} 2 \mathrm{D}$ & $58 \mathrm{C}$ disparity \\
\hline Stringent & rs12070036 & $\mathrm{BD}$ & $58 \mathrm{C}$ disparity \\
\hline Stringent & rs12381130 & T1D & $58 \mathrm{C}$ disparity \\
\hline Stringent & rs295470 & CAD & $58 \mathrm{C}$ disparity \\
\hline Stringent, relaxed & $\begin{array}{l}\text { SNP_A- } \\
1797773\end{array}$ & $\mathrm{~T} 2 \mathrm{D}, \mathrm{BD}, \mathrm{CD}$ & $58 \mathrm{C}$ disparity \\
\hline $\begin{array}{l}\text { Stringent (MHC in } \\
\text { T1D) }\end{array}$ & rs9257223 & T1D & $58 \mathrm{C}$ disparity \\
\hline Relaxed & rs11028186 & RA & 58C disparity \\
\hline Relaxed & rs12256867 & $\mathrm{T} 2 \mathrm{D}$ & $58 \mathrm{C}$ disparity \\
\hline Relaxed & rs1404223 & CAD & $58 \mathrm{C}$ disparity \\
\hline Relaxed & rs17230081 & $\mathrm{T} 2 \mathrm{D}$ & $58 \mathrm{C}$ disparity \\
\hline Relaxed & rs1842055 & CAD & $58 \mathrm{C}$ disparity \\
\hline Relaxed & rs330201 & CAD & $58 \mathrm{C}$ disparity \\
\hline Relaxed, no-call & rs4318932 & $\mathrm{T} 2 \mathrm{D}$ & $\begin{array}{l}\text { NBS/CAD/RA } \\
\text { disparity }\end{array}$ \\
\hline Relaxed & rs4473816 & RA & $58 \mathrm{C}$ disparity \\
\hline Relaxed & rs7259082 & CAD & $58 \mathrm{C}$ disparity \\
\hline Relaxed & rs9665670 & $\mathrm{BD}, \mathrm{CAD}$ & $58 \mathrm{C}$ disparity \\
\hline Relaxed, no-call & $\begin{array}{l}\text { SNP_A- } \\
1817967\end{array}$ & $C D$ & $58 \mathrm{C}$ disparity \\
\hline No-call & rs10238378 & $\mathrm{BD}$ & $58 \mathrm{C}$ disparity \\
\hline No-call & rs10485575 & $\mathrm{BD}$ & $58 \mathrm{C}$ disparity \\
\hline No-call & rs10811497 & $\mathrm{BD}$ & $58 \mathrm{C}$ disparity \\
\hline No-call & rs12428824 & $\mathrm{BD}$ & $58 \mathrm{C}$ disparity \\
\hline No-call & rs1421867 & T1D & $\begin{array}{l}\text { more than } 3 \\
\text { clusters }\end{array}$ \\
\hline No-call & rs1819829 & HT & $\begin{array}{l}\text { NBS/CAD/RA } \\
\text { disparity }\end{array}$ \\
\hline No-call & rs2039945 & $\mathrm{T} 2 \mathrm{D}$ & $58 \mathrm{C}$ disparity \\
\hline No-call & rs2804672 & HT & $\begin{array}{l}\text { NBS/CAD/RA } \\
\text { disparity }\end{array}$ \\
\hline No-call & rs6512631 & CAD & 58C disparity \\
\hline
\end{tabular}

\section{Linkage}

In the present study, concordant observations at several adjacent SNPs were not expected [10], and the analysis did not require such observations. Looking at the 28 SNPs identified by the stringent filter in Tables 2 and 3 retrospectively, one can look for evidence of linkage in the form of a significantly increased no-call rate at SNPs adjacent to the target SNP. Evidence of linkage at the 28 loci, within the SNP resolution available on the microarray platform, is summarized in Table 10.

These linkage results demonstrate that strong linkage is unusual, and that when it occurs, linkage is typically limited to one neighboring SNP. These results also suggest that linkage is more common in $\mathrm{BD}$ and $\mathrm{HT}$ than in other conditions. 


\section{Somatic deletion}

While the filters discussed previously are designed to identify gene conversion, it is possible that they also capture cases of somatic deletion. Somatic deletion at a SNP locus would be indistinguishable from somatic conversion within the flanking sequence of the SNP. Looking at the stringent filter results, approximately half of the loci have pairs of duplicons within a few megabases of each other on the same chromosome. This pattern could lead to deletions through gene conversion, improper recombination, or due to removal of sequence fragments forming hairpin-like structures [185]. Somatic duplication is also possible. For rs12381130 and rs11010908, there is no disease-related gene within any of the duplicons, while disease-related genes do occur between duplicons. (The LRP5 gene resides on the chromosome 11 interval for rs12381130, and the ANKRD26 gene resides on the chromosome 10 interval for rs11010908.) For rs9378249, the data suggest that there is a somatic deletion of the DHFRP2 pseudogene.

There is another kind of deletion that could give rise to results that might appear like gene conversion. Consider a SNP locus in which there exists a duplicon having $100 \%$ sequence identity in the flanking sequence. This duplicon would add to the signal of one of the alleles at the SNP locus.(Cross-hybridization with less that $100 \%$ identity is possible, but is ignored here.) Assuming the duplicon is not polymorphic, this additive signal would be consistent across individuals. The positions of the clusters would be different from a situation without such a duplicon, but $\mathrm{AA} / \mathrm{AB} / \mathrm{BB}$ clusters would still be able to be differentiated from one another.

Imagine a disease associated phenomenon in which there is increased deletion of the duplicon (but not the SNP region) due to improper recombination. In such a case, there would be a bias towards a loss of signal for the allele that is present in the non-polymorphic duplicon. This is the opposite bias to what one expects from gene conversion of the SNP region by its duplicon (although as discussed in Additional file 1, for conversion of major to minor alleles, such a bias is still possible).

To investigate this possibility, I re-examined the results of the stringent filter to identify cases where there is (a) $100 \%$ identity of the duplicon within the SNP's flanking sequence, and (b) a change in the allele distribution away from the allele in the duplicon. There is one such SNP, namely rs9551988, that accounts for three of the five observations (Table S1) where the allele frequency changes away from the allele in the non-polymorphic duplicon. Given the additional information that the duplicons for rs9551988 are $500 \mathrm{~kb}$ away from each other on the same chromosome and in the same orientation, it is reasonable to infer that deletion is the likely explanation for the results observed at this locus.

Now imagine a disease associated phenomenon in which there is increased deletion of the SNP region (but not the non-polymorphic duplicon) due to improper recombination. In such a case, there would be a bias towards a relative loss of signal for the allele that is not present in the non-polymorphic duplicon. This is the same bias that one expects from gene conversion of the SNP region by its duplicon. I therefore re-examined the results of the stringent filter to identify cases where there is (a) 100\% identity of the duplicon within the SNP's flanking sequence, and (b) a change in the allele distribution towards the allele in the duplicon. There are four such cases, namely rs669980, rs935019, SNP_A-1797773, and rs9839841. Of these, only rs935019 represents a case with nearby aligned duplicons on the same chromosome. For rs935019, variation

Table 10 Linkage between stringent-filter SNPs and adjacent SNPs

\begin{tabular}{|c|c|c|c|c|}
\hline Stringent test SNP & Disease & Adjacent SNP & $P$ & Comments \\
\hline \multirow[t]{2}{*}{ rs9551988 } & $\mathrm{HT}$ & rs3858741 & $3.2 \times 10^{-12}$ & $1.1 \mathrm{~kb}$ away, within same duplicon \\
\hline & $\mathrm{BD}$ & rs3858741 & $8.9 \times 10^{-8}$ & (No linkage for CAD.) \\
\hline \multirow[t]{2}{*}{ rs9378249 } & $\mathrm{BD}$ & rs2596477 & $3.7 \times 10^{-7}$ & 22 bp away, within same duplicon \\
\hline & $\mathrm{HT}$ & rs2596477 & $6.0 \times 10^{-4}$ & \\
\hline \multirow[t]{3}{*}{ rs841245 } & HT & rs12229182 & $2.5 \times 10^{-6}$ & $12 \mathrm{~kb}$ away, within same duplicon \\
\hline & & rs841636 & $1.7 \times 10^{-5}$ & 12 kb away, within same duplicon \\
\hline & & & & (No linkage at intervening SNP rs10842853) \\
\hline \multirow[t]{2}{*}{ SNP_A-1948953 } & $\mathrm{BD}$ & rs9893203 & $5.4 \times 10^{-4}$ & $8.6 \mathrm{~kb}$ away \\
\hline & HT & rs9893203 & $6.8 \times 10^{-4}$ & \\
\hline rs11010908 & $\mathrm{T} 2 \mathrm{D}$ & rs17561365 & $1.2 \times 10^{-3}$ & $3.2 \mathrm{~kb}$ away, within same duplicon \\
\hline
\end{tabular}

The $P$ value corresponds to a one-sided chi-squared test for an increased no-call rate. $P$ values for excluded SNPs were all above $2 \times 10^{-3}$. 
in copy number has been observed in cloning experiments [65], suggesting that deletion is the most likely explanation for this locus.

An additional example was observed during the examination of SNPs using BLAST to determine whether they reside in a region with homology elsewhere in the genome. rs2812 met the stringent filter conditions for CAD except that it did not reside in a duplicated region. Nevertheless, a 400 bp duplicon occurred both upstream and downstream of rs2812, together spanning a $2 \mathrm{~kb}$ region including the SNP. rs2812 is located within the PECAM1 gene, which has previously been associated with CAD [186-188]. Out of approximately 250 SNPs that were examined in this way, rs2812 was the only one for which this kind of duplication pattern was observed. Nevertheless, the present study was not designed to identify such patterns, and additional longer-range (or inter-chromosomal) duplication that increases the likelihood of sequence deletion may exist.

\section{Known de-novo non-allelic conversion sites}

Five pairs of genes have been identified as loci of de-novo germ-line gene conversion between non-allelic regions, leading to a disease phenotype [1]; see Table 11. If these conversion events are frequent enough to be noticed even in the germline, then such loci may be likely to be sites of relatively frequent somatic conversion. I therefore examine SNPs located in duplicons related to these gene pairs to determine whether the cluster plots support this hypothesis.

I consider all SNPs appearing in one of the two duplicons shared by the two genes. Coverage is limited by the resolution of the microarray. In fact, no SNPs are available for the CYP21A1P/CYP21A2 genes. For the SBDSP/SBDS pair, there are four almost-contiguous segmental duplications in the segmental duplication database, spanning just over $500 \mathrm{~kb}$. I consider all SNPs in all of the four duplicons. I visually inspected the cluster plots for the SNPs in the corresponding duplicons. The target pattern is one in which for every population (including controls) there is a substantial number of points between clusters. The results of the visual cluster plot analysis are summarized in Table 12. The visual analysis is supported by the WTCCC quality control procedures: for seven of the nine identified SNPs (all

Table 11 De-Novo conversion events in disease [1]

\begin{tabular}{lll}
\hline Disease & Donor & Acceptor \\
\hline Atypical haemolytic uraemic syndrome & CFHR1 & CFH \\
Congenital adrenal hyperplasia & CYP21A1P & CYP21A2 \\
Neural tube defects & FOLR1P & FOLR1 \\
Hereditary persistence of fetal haemoglobin & HBG2 & HBG1 \\
Shwachman-Diamond syndrome & SBDSP & SBDS \\
\hline
\end{tabular}

Table 12 Possible conversion in duplicons for genes previously observed to have undergone germ-line conversion

\begin{tabular}{lll}
\hline Genes & $\begin{array}{l}\text { Number of } \\
\text { SNPs } \\
\text { in duplicons }\end{array}$ & $\begin{array}{l}\text { SNPs showing } \\
\text { possible conversion }\end{array}$ \\
\hline CFHR1/CFH & 7 & rs395998, rs413979 \\
FOLR1P/FOLR1 & 5 & rs1540087 \\
HBG2/HBG1 & 3 & rs6578592 \\
SBDSP/SBDS & 38 & rs4717344, SNP_A-1849003, \\
& & rs4718487, rs1465306, rs2003206 \\
\hline
\end{tabular}

Events are identified by visually inspecting cluster plots for all SNPs in the region.

except rs6578592 and rs1465306) the SNP was excluded for quality control reasons such as departure from HWE in the control population. (One additional SNP, rs1880278, was also excluded for quality control reasons but did not show features predicted for gene conversion.)

Given the small sample size and sparse coverage of the duplicons, the results of Table 12 are suggestive, but far from definitive.

\section{Disease-specific patterns}

Based on the SCE data, RA was predicted to be a local disease. Four SNPs that are associated with RA (rs4988327, rs10768666, rs4236384, rs9976299) have cluster plots in which RA alone has an increased number of no-calls. When other disease populations have correlated behavior, the RA population sometimes appears to remain close to the control population, as exemplified in Figure 5. In contrast, no other disease population has an associated SNP for which that population alone has an increased no-call rate.

These results are broadly consistent with a view of RA as a local disease, and of the remaining diseases as global diseases. The distinction is not clear-cut, however, since there are RA-associated SNPs with no-call behavior that is similar across multiple diseases.

An alternative interpretation of the distinctness of RA is based on the observation that lymphocytes may be the initiators of RA pathogenesis. Since lymphocytes are the cells being genotyped, lymphocyte-specific autoimmune dynamics could amplify the signal attributable to pathogenic mutations. For example, a mutation in a $\mathrm{T}$ cell that leads to cell activation and replication would substantially increase the population of cells exhibiting the mutation. Of the four SNPs showing RA-specific spread in the cluster plots, rs9976299 is notable for being within the ITGB2 gene which encodes the CD18 adhesion molecule. CD18 expression is upregulated in macrophages and T-cells in the peripheral blood and synovial fluid of RA patients $[183,184]$. 
$\mathrm{BD}$ and $\mathrm{HT}$ co-occur at four different stringent-filter SNPs. Three of these SNPs display similar linkage patterns with neighboring SNPs for both BD and HT. These factors suggest that BD and HT may have a common ultimate cause that is different from the other five diseases. A general similarity between HT and BD has previously been identified using a classification algorithm over the same WTCCC data set [189]. Individuals with BD have a more than twofold increased risk of HT [190].

\section{Discussion}

Based on prior data for loci such as IDS [3,4], disease related genes were sought in one of several duplicons, only one of which contains the identified SNP. For 8 out of the 28 stringent filter SNPs, the disease related gene is on a duplicon not containing the SNP, emphasizing the importance of examining all duplicons. Such genes would not be identified using a conventional association study.

Confounding factors could perturb cluster plots, potentially leading to false associations. Loci that did not meet the WTCCC quality control requirements have been excluded. The WTCCC reports a disparity between the NBS/RA/CAD cohorts and the other cohorts for some SNPs [11]; such disparities are rare among the SNPs meeting the filter conditions (Table 9). Additional quality control issues not identified by the WTCCC are possible. Nevertheless, it is hard to imagine how a quality control artifact could lead to populationspecific effects that correlate with disease related genes.

Copy-number variation can be discounted as a general explanation for the observed phenomena, since none of the stringent test SNPs (and only one of the no-call SNPs) showed more than three clusters. Further, few of the stringent filter SNPs are within known CNV loci (Additional file 1). Even if copy number variation was the mechanism responsible for some of the present results, the results would still be interesting as novel cohort-specific associations.

The present paper provides support for the hypothesis that many complex diseases are caused in part by somatic mutation in regions with homology elsewhere in the genome. Diseases such as cancer often display gross karyotypic changes that could be due to improper recombination between nonallelic homologous regions in somatic tissue. Because detection of somatic mutations is technically much more demanding than that of germline mutations, somatic gene-conversion events in cancer have probably been underestimated [1].

Some puzzling epidemiological features of autoimmune diseases are consistent with a somatic mutation hypothesis. Association with viruses can be explained by the mutagenic actions of those viruses. Associations of autoimmune disease with higher latitudes has been hypothesized to relate to lower vitamin D levels [191]; vitamin $\mathrm{D}$ is associated with lower rates of doublestrand breaks [192] and with protection from viral infections [193]. Complex inheritance patterns spanning multiple diseases would result from a common underlying genetic susceptibility based on sequence homology, combined with stochastic effects such as tissue-specific viral infection.

In order to be identified as a conversion region in this study, the region must contain a locus that is within the SNP repertoire of the microarray chip. A substantial amount of somatic gene conversion might affect loci with alleles that are fixed in the population. If so, alternative platforms will be needed to detect such conversion. It is likely that there is additional disease-specific somatic gene conversion that the present study has not detected even among the covered SNPs. Spread in the cluster plots might not be apparent if a particular disease-causing somatic mutation was rare enough that the perturbation was small relative to experimental variation.

On the other hand, common gene conversion events might preferentially include SNP loci. If a conversion event is common in somatic tissues, it may also be relatively common in the germ-line. If the germ-line event is not deleterious, a polymorphism could result. The consequences of somatic and germ-line changes are different, and a somatic mutation may cause disease where a germ-line change does not. For example, a somatic mutation may result in a novel protein that is immunogenic. Alternatively, some of the loci associated with a conversion event may be phenotypically neutral, and these may lead to polymorphisms as a result of partial conversion events in the germ-line.

The phenotype of a somatic mutation is likely to be very different from the phenotype of a germ-line mutation. Outside of cancer, there is very little data about phenotypes associated with somatic mutations. It is therefore dificult to correlate the observations of this paper with existing knowledge about somatic mutation. Correlations with genomewide studies of disease associated polymorphisms are possible in principle. However, given the methodologies used in those studies (for example, requiring multiple concordant SNPs [11]), it is not expected that correlations will be found given the absence of linkage disequilibrium for gene conversion [10].

It may well be that somatic gene conversion is, in some cases, a normal adaptive phenomenon. Such effects might be detectable using SNP microarrays by examining the intensity plots directly without employing a calling algorithm. The quality control protocols of SNP array studies typically exclude loci where the called allele frequencies depart from HWE in the control population, which would exclude loci for which somatic gene 
conversion was common. It may be worth re-examining such loci, particularly those in duplicated regions.

The present report suggests that somatic gene conversion is associated with mutations and genomic rearrangements that lead to disease. Working backwards, one could generate hypotheses for further study by identifying genomic regions with high degrees of homology that contain disease-relevant genes. For example, the BRCA1 gene that is involved in DNA stability and repair pathways [194] itself contains a segmental duplication that includes part of the gene and its promoter region $[195,196]$. Some BRCA1-related cancers appear to be caused by gene conversion events in individuals carrying one mutant BRCA1 allele [197]. Once BRCA1 function is compromised, gene conversion and rearrangement at other loci may become more frequent.

Gene conversion could be a cause of the disease phenotype, or it could alternatively be a side-effect of an underlying disease-causing genetic disorder with no direct bearing on the phenotype. The fact that disease associations are found for most of the stringent filter SNPs is strongly suggestive of a causative link in which the specific conversion events are the proximate causes of the phenotype.

I have used the output of the Chiamo algorithm without modification. Spread is inferred from a high number of no-call results at a locus. While this method of inferring spread appears to have been effective, more effective methods might be possible. Methods could measure suitably defined 'spread statistics' given allele intensity distributions for several populations.

The success of the analysis supports the hypothesis suggested by the sister chromatid exchange studies that DNA in lymphocytes undergoes similar transformations to DNA in tissues affected by disease. In principle, it may be possible to test for various somatic mutations using a blood sample. Specialized microarrays could be developed to detect specific sequences resulting from common somatic mutations.

Several important questions remain. The present study does not allow the quantification of risk associated with any particular gene conversion locus. Even the identification of which individuals have substantial conversion at a locus is approximate. Locus-specific experimental studies of conversion frequencies in health and disease are needed.

The present study also does not quantify the degree of conversion necessary to cause disease. In lymphocytes, for example, mutations in a very small number of cells could cause disease if those cells undergo clonal expansion. In other tissues, many cells might need to be mutated before tissue function is compromised. Stem cell mutations (which may be relatively common due to frequent mitosis) could lead to a regular inflow of mutated cells.
Disease associations with a number of specific genes have been suggested by the present work. Changes at these loci in somatic tissues may represent the proximate cause of disease. Nevertheless, the ultimate cause of disease is the factor that causes the DNA damage. Environmental factors are likely to play a significant role. The association of the folate-dependent thymine nucleotide synthesis pathway with several diseases, together with an increase in the frequency of SCEs under methotrexate treatment [198], also suggests another kind of ultimate cause in which impaired DNA synthesis leads to homology-driven repair [199].

\section{Conclusions}

That somatic gene conversion may occur frequently has been previously suggested, but progress has been hampered by the technical difficulty of measuring somatic gene conversion on a large scale [1]. The present study is the first to use genome-scale SNP data to infer somatic gene conversion loci in specific populations. For more than $75 \%$ of the loci, genes within the locus associate with the corresponding disease in a manner consistent with known gene/disease associations.

Any single association identified in this report should be considered tentative, and subject to experimental confirmation. Nevertheless, taken together, the associations provide compelling evidence that somatic gene conversion and/or somatic deletion at particular loci influence each of the seven studied diseases. The techniques developed are not specific to the WTCCC data, and could be applied to other data sets to identify putative gene conversion for other diseases.

\section{Additional material}

Additional file 1: Supporting text and tables. Detailed information about the identified SNPs, copy number variation, SNP interactions, and the mock study.

Additional file 2: Zip archive containing cluster plots for all SNPs mentioned in the main text. The $58 \mathrm{C}$ and NBS populations are approximatel 1,500 while the other populations are each about 2,000.

\section{Abbreviations \\ BD: bipolar disorder; bp: base pair; CAD: coronary artery disease; DSB: double strand break; HT: hypertension; kb: kilobases; RA: rheumatoid arthritis; SCE: sister chromatid exchange; SNP: single nucleotide polymorphism; T1D: type- 1 diabetes; T2D: type-2 diabetes; WTCCC: Wellcome Trust Case Control consortium.}

\section{Acknowledgements}

This work was funded by the NIH under award U54-CA121852. The NIH played no role in the study design, data collection/analysis, or in the decision to submit the manuscript for publication. This study makes use, with permission, of data generated by the Wellcome Trust Case Control Consortium. A full list of the investigators who contributed to the generation of the data is available from http://www.wtccc.org.uk. Funding for the WTCCC project was provided by the Wellcome Trust under award 
076113. Access to the data was approved by an Institutional Review Board at Columbia University. The author thanks Itsik Pe'er and Martin Lindquist for helpful discussions.

\section{Competing interests}

The author declares that he has no competing interests

Received: 15 October 2010 Accepted: 3 February 2011

Published: 3 February 2011

\section{References}

1. Chen JM, Cooper DN, Chuzhanova N, Férec C, Patrinos GP: Gene conversion: mechanisms, evolution and human disease. Nat Rev Genet 2007, 8:762-775.

2. Johnson $\mathrm{RD}$, Jasin M: Double-strand-break-induced homologous recombination in mammalian cells. Biochem Soc Trans 2001, 29:196-201.

3. Lagerstedt K, Karsten SL, Carlberg BM, Kleijer WJ, Tönnesen T, Pettersson U, Bondeson ML: Double-strand breaks may initiate the inversion mutation causing the Hunter syndrome. Hum Mol Genet 1997, 6:627-633.

4. Bunge S, Rathmann M, Steglich C, Bondeson ML, Tylki-Szymanska A, Popowska E, Gal A: Homologous nonallelic recombinations between the iduronate-sulfatase gene and pseudogene cause various intragenic deletions and inversions in patients with mucopolysaccharidosis type II. Eur J Hum Genet 1998, 6:492-500.

5. Colot V, Maloisel L, Rossignol JL: Interchromosomal transfer of epigenetic states in Ascobolus: transfer of DNA methylation is mechanistically related to homologous recombination. Cell 1996, 86:855-864.

6. Jeffreys AJ, May CA: Intense and highly localized gene conversion activity in human meiotic crossover hot spots. Nat Genet 2004, 36:151-156.

7. Catasti P, Chen X, Mariappan SV, Bradbury EM, Gupta G: DNA repeats in the human genome. Genetica 1999, 106:15-36.

8. Tan Y, Zhang B, Wu T, Skogerbø G, Zhu X, Guo X, He S, Chen R: Transcriptional inhibiton of Hoxd4 expression by miRNA-10a in human breast cancer cells. BMC Mol Biol 2009, 10:12.

9. Hawkins PG, Morris KV: RNA and transcriptional modulation of gene expression. Cell Cycle 2008, 7:602-607.

10. Wall JD: Close look at gene conversion hot spots. Nat Genet 2004, 36:114-115.

11. The Wellcome Trust Case Control Consortium: Genome-wide association study of 14,000 cases of seven common diseases and 3,000 shared controls. Nature 2007, 447:661-678.

12. Sonoda E, Sasaki MS, Morrison C, Yamaguchi-Iwai Y, Takata M, Takeda S: Sister chromatid exchanges are mediated by homologous recombination in vertebrate cells. Mol Cell Biol 1999, 19:5166-5169.

13. Wilcosky T, Rynard S: Sister chromatid exchange. In Biological Markers in Epidemiology. Edited by: Hulka B, Wilcosky T, Griffth J. New York: Oxford University Press; 1990:

14. Kang MH, Genser D, Elmadfa I: Increased sister chromatid exchanges in peripheral lymphocytes of patients with Crohn's disease. Mutat Res 1997, 381:141-148.

15. Pernice F, Floccari F, Caccamo C, Belghity N, Mantuano S, Pacilè ME, Romeo A, Nostro L, Barillà A, Crascì E, Frisina N, Buemi M: Chromosomal damage and atherosclerosis. A protective effect from simvastatin. Eur J Pharmacol 2006, 532:223-229.

16. Cinkilic N, Kiyici S, Celikler S, Vatan O, Oz Gul O, Tuncel E, Bilaloglu R: Evaluation of chromosome aberrations, sister chromatid exchange and micronuclei in patients with type-1 diabetes mellitus. Mutat Res 2009, 676:1-4.

17. Sheth F, Patel P, Vaidya A, Vaidya R, Sheth J: Increased frequency of sister chromatid exchanges in patients with type II diabetes. Curr Sci 2006, 90:236-240.

18. Jarmalaite S, Mierauskiene J, Beitas K, Ranceva J, Lazutka JR, Butrimiene I: Sister chromatid exchanges and cell proliferative abilities in cultured peripheral blood lymphocytes of patients with rheumatoid and reactive arthritis. Clin Exp Rheumatol 2006, 24:677-682.

19. Vormittag W: Structural chromosomal aberration rates and sisterchromatid exchange frequencies in females with type 2 (non-insulindependent) diabetes. Mutat Res 1985, 143:117-119.

20. Senécal-Quevillon M, Duquette $P$, Richer CL: Analysis of sister-chromatid exchanges (SCEs) in familial and sporadic multiple sclerosis. Mutat Res 1986, 161:65-74.
21. Palmer RG, Doré CJ, Henderson L, Denman AM: Sister-chromatid exchange frequencies in fibroblasts and lymphocytes of patients with systemic lupus erythematosus. Mutat Res 1987, 177:125-132.

22. Palmer RG, Doré CJ, Denman AM: Sister-chromatid exchange frequencies in lymphocytes of controls and patients with connective tissue diseases. Mutat Res 1986, 162:113-120.

23. Liang F, Han M, Romanienko PJ, Jasin M: Homology-directed repair is a major double-strand break repair pathway in mammalian cells. Proc Natl Acad Sci USA 1998, 95:5172-5177.

24. McLendon R, Friedman A, Bigner D, Van Meir EG, Brat DJ, Mastrogianakis GM, Olson JJ, Mikkelsen T, Lehman N, Aldape K, Yung WK, Bogler O, Weinstein JN, VandenBerg S, Berger M, Prados M, Muzny D, Morgan M, Scherer S, Sabo A, Nazareth L, Lewis L, Hall O, Zhu Y, Ren Y, Alvi O, Yao J, Hawes A, Jhangiani S, Fowler G, et al: Comprehensive genomic characterization defines human glioblastoma genes and core pathways. Nature 2008, 455:1061-1068.

25. Bailey JA, Yavor AM, Massa HF, Trask BJ, Eichler EE: Segmental duplications: organization and impact within the current human genome project assembly. Genome Res 2001, 11:1005-1017.

26. lafrate AJ, Feuk L, Rivera MN, Listewnik ML, Donahoe PK, Qi Y, Scherer SW, Lee C: Detection of large-scale variation in the human genome. Nat Genet 2004, 36:949-951.

27. Rubin GL, Sharp S, Jones AL, Glatt H, Mills JA, Coughtrie MW: Design, production and characterization of antibodies discriminating between the phenol- and monoamine-sulphating forms of human phenol sulphotransferase. Xenobiotica 1996, 26:1113-1119.

28. Eisenhofer G, Coughtrie MW, Goldstein DS: Dopamine sulphate: an enigma resolved. Clin Exp Pharmacol Physiol Suppl 1999, 26:41-53.

29. Langmann T, Moehle C, Mauerer R, Scharl M, Liebisch G, Zahn A, Stremmel W, Schmitz G: Loss of detoxification in inammatory bowel disease: dysregulation of pregnane $\times$ receptor target genes. Gastroenterology 2004, 127:26-40.

30. Imielinski M, Baldassano RN, Griffths A, Russell RK, Annese V, Dubinsky M, Kugathasan S, Bradfield JP, Walters TD, Sleiman P, Kim CE, Muise A, Wang K, Glessner JT, Saeed S, Zhang H, Frackelton EC, Hou C, Flory JH, Otieno G, Chiavacci RM, Grundmeier R, Castro M, Latiano A, Dallapiccola B, Stempak J, Abrams DJ, Taylor K, McGovern D, Heyman MB, et al: Common variants at five new loci associated with early-onset inammatory bowel disease. Nat Genet 2009, 41:1335-1340.

31. Nakamura T, Watanabe A, Fujino T, Hosono T, Michikawa M: Apolipoprotein E4(1-272) fragment is associated with mitochondrial proteins and affects mitochondrial function in neuronal cells. Mol Neurodegener 2009, 4:35.

32. Restivo NL, Srivastava MD, Schafer IA, Hoppel CL: Mitochondrial dysfunction in a patient with crohn disease: possible role in pathogenesis. J Pediatr Gastroenterol Nutr 2004, 38:534-538.

33. Kumar RA, KaraMohamed S, Sudi J, Conrad DF, Brune C, Badner JA, Gilliam TC, Nowak NJ, Cook EH, Dobyns WB, Christian SL: Recurrent 16p11.2 microdeletions in autism. Hum Mol Genet 2008, 17:628-638.

34. Weiss LA, Shen Y, Korn JM, Arking DE, Miller DT, Fossdal R, Saemundsen E, Stefansson H, Ferreira MA, Green T, Platt OS, Ruderfer DM, Walsh CA, Altshuler D, Chakravarti A, Tanzi RE, Stefansson K, Santangelo SL, Gusella JF, Sklar P, Wu BL, Daly MJ: Association between microdeletion and microduplication at 16p11.2 and autism. N Engl J Med 2008, 358:667-675.

35. Wakefield AJ, Ashwood P, Limb K, Anthony A: The significance of ileocolonic lymphoid nodular hyperplasia in children with autistic spectrum disorder. Eur J Gastroenterol Hepatol 2005, 17:827-836.

36. Tsao CY, Mendell JR: Autistic disorder in 2 children with mitochondrial disorders. J Child Neurol 2007, 22:1121-1123.

37. Oliveira G, Diogo L, Grazina M, Garcia P, Ataíde A, Marques C, Miguel T, Borges L, Vicente AM, Oliveira CR: Mitochondrial dysfunction in autism spectrum disorders: a population-based study. Dev Med Child Neurol 2005, 47:185-189.

38. Crouzet J, Levy-Schil S, Cameron B, Cauchois L, Rigault S, Rouyez MC, Blanche F, Debussche L, Thibaut D: Nucleotide sequence and genetic analysis of a 13.1-kilobase-pair Pseudomonas denitrificans DNA fragment containing five cob genes and identification of structural genes encoding $\mathrm{Cob}(\mathrm{I})$ alamin adenosyltransferase, cobyric acid synthase, and bifunctional cobinamide kinase-cobinamide phosphate guanylyltransferase. J Bacteriol 1991, 173:6074-6087.

39. Rodionov DA, Vitreschak AG, Mironov AA, Gelfand MS: Comparative genomics of the vitamin B12 metabolism and regulation in prokaryotes. J Biol Chem 2003, 278:41148-41159. 
40. Heldt $D$, Lawrence AD, Lindenmeyer M, Deery E, Heathcote P, Rigby SE, Warren MJ: Aerobic synthesis of vitamin B12: ring contraction and cobalt chelation. Biochem Soc Trans 2005, 33:815-819.

41. Christensen PA, Brynskov J, Gimsing P, Petersen J: Vitamin B12 binding proteins (transcobalamin and haptocorrin) in serum and synovial uid of patients with rheumatoid arthritis and traumatic synovitis. Scand J Rheumatol 1983, 12:268-272.

42. Sattar MA, Das KC: Plasma vitamin B12 binding proteins correlate with disease activity in patients with rheumatoid arthritis. Med Lab Sci 1991, 48:36-42.

43. Segal R, Baumoehl Y, Elkayam O, Levartovsky D, Litinsky I, Paran D, Wigler I, Habot B, Leibovitz A, Sela BA, Caspi D: Anemia, serum vitamin B12, and folic acid in patients with rheumatoid arthritis, psoriatic arthritis, and systemic lupus erythematosus. Rheumatol Int 2004, 24:14-19.

44. Yamashiki M, Nishimura A, Kosaka Y: Effects of methylcobalamin (vitamin B12) on in vitro cytokine production of peripheral blood mononuclear cells. J Clin Lab Immunol 1992, 37:173-182.

45. Lazzerini PE, Capecchi PL, Selvi E, Lorenzini S, Bisogno S, Galeazzi M, Laghi Pasini F: Hyperhomocysteinemia: a cardiovascular risk factor in autoimmune diseases? Lupus 2007, 16:852-862.

46. Beyersmann D, Hartwig A: The genetic toxicology of cobalt. Toxicol Appl Pharmacol 1992, 115:137-145.

47. Gong J, Sun Z, Li P: CIDE proteins and metabolic disorders. Curr Opin Lipidol 2009, 20:121-126.

48. Nordström EA, Rydén M, Backlund EC, Dahlman I, Kaaman M, Blomqvist L, Cannon B, Nedergaard J, Arner P: A human-specific role of cell deathinducing DFFA (DNA fragmentation factor-alpha)-like effector A (CIDEA) in adipocyte lipolysis and obesity. Diabetes 2005, 54:1726-1734.

49. Puri V, Ranjit S, Konda S, Nicoloro SM, Straubhaar J, Chawla A, Chouinard M, Lin C, Burkart A, Corvera S, Perugini RA, Czech MP: Cidea is associated with lipid droplets and insulin sensitivity in humans. Proc Natl Acad Sci USA 2008, 105:7833-7838

50. Van Gaal LF, Mertens IL, De Block CE: Mechanisms linking obesity with cardiovascular disease. Nature 2006, 444:875-880.

51. Shin C, Manley JL: The SR protein SRp38 represses splicing in M phase cells. Cell 2002, 111:407-417.

52. Blencowe BJ: Splicing regulation: the cell cycle connection. Curr Biol 2003, 13:R149-151.

53. Shin C, Feng Y, Manley JL: Dephosphorylated SRp38 acts as a splicing repressor in response to heat shock. Nature 2004, 427:553-558.

54. Feng $Y$, Valley MT, Lazar J, Yang AL, Bronson RT, Firestein S, Coetzee WA Manley JL: SRp38 regulates alternative splicing and is required for $\mathrm{Ca}(2+)$ handling in the embryonic heart. Dev Cell 2009, 16:528-538.

55. Fox AH, Bond CS, Lamond Al: P54nrb forms a heterodimer with PSP1 that localizes to paraspeckles in an RNA-dependent manner. Mol Biol Cell 2005, 16:5304-5315.

56. Prasanth KV, Prasanth SG, Xuan Z, Hearn S, Freier SM, Bennett CF Zhang $M Q$, Spector DL: Regulating gene expression through RNA nuclear retention. Cell 2005, 123:249-263.

57. Devés R, Boyd CA: Transporters for cationic amino acids in animal cells: discovery, structure, and function. Physiol Rev 1998, 78:487-545.

58. Steinberg HO, Baron AD: Vascular function, insulin resistance and fatty acids. Diabetologia 2002, 45:623-634.

59. Cleland SJ, Petrie JR, Ueda S, Elliott HL, Connell JM: Insulin as a vascular hormone: implications for the pathophysiology of cardiovascular disease. Clin Exp Pharmacol Physiol 1998, 25:175-184

60. González M, Flores C, Pearson JD, Casanello P, Sobrevia L: Cell signallingmediating insulin increase of mRNA expression for cationic amino acid transporters-1 and -2 and membrane hyperpolarization in human umbilical vein endothelial cells. Pugers Arch 2004, 448:383-394

61. Muñoz M, Sweiry JH, Mann GE: Insulin stimulates cationic amino acid transport activity in the isolated perfused rat pancreas. Exp Physiol 1995, 80:745-753.

62. McCord N, Ayuk P, McMahon M, Boyd RC, Sargent I, Redman C: System y+ arginine transport and NO production in peripheral blood mononuclear cells in pregnancy and preeclampsia. Hypertension 2006, 47:109-115.

63. Yanik M, Vural H, Tutkun H, Zoroğlu SS, Savaş HA, Herken H, Koçyiğit A, Keleş $\mathrm{H}$, Akyol $\mathrm{O}$ : The role of the arginine-nitric oxide pathway in the pathogenesis of bipolar affective disorder. Eur Arch Psychiatry Clin Neurosci 2004, 254:43-47.
64. Hoekstra R, Fekkes D, Pepplinkhuizen L, Loonen AJ, Tuinier S, Verhoeven WM: Nitric oxide and neopterin in bipolar affective disorder. Neuropsychobiology 2006, 54:75-81.

65. Colin Y, Le Van Kim C, Tsapis A, Clerget M, d'Auriol L, London J, Galibert F, Cartron JP: Human erythrocyte glycophorin C. Gene structure and rearrangement in genetic variants. J Biol Chem 1989, 264:3773-3780.

66. Colin Y: Gerbich blood groups and minor glycophorins of human erythrocytes. Transfus Clin Biol 1995, 2:259-268

67. Sanguinetti MC, Jiang C, Curran ME, Keating MT: A mechanistic link between an inherited and an acquired cardiac arrhythmia: HERG encodes the IKr potassium channel. Cell 1995, 81:299-307.

68. Kupershmidt S, Yang IC, Hayashi K, Wei J, Chanthaphaychith S, Petersen Cl, Johns DC, George AL, Roden DM, Balser JR: The IKr drug response is modulated by KCR1 in transfected cardiac and noncardiac cell lines. FASEB J 2003, 17:2263-2265

69. Nakajima T, Hayashi K, Viswanathan PC, Kim MY, Anghelescu M, Barksdale KA, Shuai W, Balser JR, Kupershmidt S: HERG is protected from pharmacological block by alpha-1,2-glucosyltransferase function. J Biol Chem 2007, 282:5506-5513

70. Michels G, Er F, Khan IF, Endres-Becker J, Brandt MC, Gassanov N, Johns DC, Hoppe UC: K+ channel regulator KCR1 suppresses heart rhythm by modulating the pacemaker current If. PLOS ONE 2008, 3:e1511.

71. Petersen Cl, McFarland TR, Stepanovic SZ, Yang P, Reiner DJ, Hayashi K, George AL, Roden DM, Thomas JH, Balser JR: In vivo identification of genes that modify ether-a-go-go-related gene activity in Caenorhabditis elegans may also affect human cardiac arrhythmia. Proc Natl Acad Sci USA 2004, 101:11773-11778.

72. Bonifacino JS, Hurley JH: Retromer. Curr Opin Cell Biol 2008, 20:427-436.

73. Zhao X, Nothwehr S, Lara-Lemus R, Zhang BY, Peter H, Arvan P: Dominantnegative behavior of mammalian Vps35 in yeast requires a conserved PRLYL motif involved in retromer assembly. Traffic 2007, 8:1829-1840.

74. Berggren S, Gall C, Wollnitz N, Ekelund M, Karlbom U, Hoogstraate J, Schrenk D, Lennernäs H: Gene and protein expression of P-glycoprotein, MRP1, MRP2, and CYP3A4 in the small and large human intestine. Mol Pharm 2007, 4:252-257

75. Wagner LA, Christensen CJ, Dunn DM, Spangrude GJ, Georgelas A, Kelley L, Esplin MS, Weiss RB, Gleich GJ: EGO, a novel, noncoding RNA gene, regulates eosinophil granule protein transcript expression. Blood 2007, 109:5191-5198

76. Lee B, Gai W, Laychock SG: Proteasomal activation mediates downregulation of inositol 1,4,5-trisphosphate receptor and calcium mobilization in rat pancreatic islets. Endocrinology 2001, 142:1744-1751.

77. Roach JC, Deutsch K, Li S, Siegel AF, Bekris LM, Einhaus DC, Sheridan CM Glusman G, Hood L, Lernmark A, Janer M: Genetic mapping at 3-kilobase resolution reveals inositol 1,4,5-triphosphate receptor 3 as a risk factor for type 1 diabetes in Sweden. Am J Hum Genet 2006, 79:614-627.

78. Qu HQ, Marchand L, Szymborski A, Grabs R, Polychronakos C: The association between type 1 diabetes and the ITPR3 gene polymorphism due to linkage disequilibrium with HLA class II. Genes Immun 2008, 9:264-266

79. Howson JM, Walker NM, Clayton D, Todd JA: Confirmation of HLA class II independent type 1 diabetes associations in the major histocompatibility complex including HLA-B and HLA-A. Diabetes Obes Metab 2009, 11(Suppl 1):31-45.

80. Purcell SM, Wray NR, Stone JL, Visscher PM, O'Donovan MC, Sullivan PF, Sklar P, Purcell SM, Wray NR, Stone JL, Visscher PM, O'Donovan MC, Sullivan PF, Sklar P, Purcell SM, Stone JL, Sullivan PF, Ruderfer DM, McQuillin A, Morris DW, O'Dushlaine CT, Corvin A, Holmans PA, O'Donovan MC, Sklar P, Wray NR, Macgregor S, Sklar P, Sullivan PF, O'Donovan $\mathrm{MC}$, et al: Common polygenic variation contributes to risk of schizophrenia and bipolar disorder. Nature 2009, 460:748-752.

81. Duthie SJ, Hawdon A: DNA instability (strand breakage, uracil misincorporation, and defective repair) is increased by folic acid depletion in human lymphocytes in vitro. FASEB J 1998, 12:1491-1497.

82. Wahlestedt C: Natural antisense and noncoding RNA transcripts as potential drug targets. Drug Discov Today 2006, 11:503-508.

83. Yelin R, Dahary D, Sorek R, Levanon EY, Goldstein O, Shoshan A, Diber A Biton S, Tamir Y, Khosravi R, Nemzer S, Pinner E, Walach S, Bernstein J, Savitsky K, Rotman G: Widespread occurrence of antisense transcription in the human genome. Nat Biotechnol 2003, 21:379-386. 
84. Demirhan O, Tastemir D, Sertdemir Y: The expression of folate sensitive fragile sites in patients with bipolar disorder. Yonsei Med J 2009, 50:137-141.

85. Kempisty B, Sikora J, Lianeri M, Szczepankiewicz A, Czerski P, Hauser J, Jagodzinski PP: G polymorphisms are associated with bipolar disorder and schizophrenia. Psychiatr Genet 2007, 17:177-181.

86. Markan S, Sachdeva M, Sehrawat BS, Kumari S, Jain S, Khullar M: MTHFR 677 CT/MTHFR 1298 CC genotypes are associated with increased risk of hypertension in Indians. Mol Cell Biochem 2007, 302:125-131.

87. Gilbody S, Lewis S, Lightfoot T: Methylenetetrahydrofolate reductase (MTHFR) genetic polymorphisms and psychiatric disorders: a HuGE review. Am J Epidemiol 2007, 165:1-13.

88. Stehouwer CD, van Guldener C: Does homocysteine cause hypertension? Clin Chem Lab Med 2003, 41:1408-1411.

89. Forman JP, Rimm EB, Stampfer MJ, Curhan GC: Folate intake and the risk of incident hypertension among US women. JAMA 2005, 293:320-329.

90. Serra-Pagès C, Medley QG, Tang M, Hart A, Streuli M: Liprins, a family of LAR transmembrane protein-tyrosine phosphatase-interacting proteins. $J$ Biol Chem 1998, 273:15611-15620.

91. Kriajevska M, Fischer-Larsen M, Moertz E, Vorm O, Tulchinsky E, Grigorian M, Ambartsumian N, Lukanidin E: Liprin beta 1, a member of the family of LAR transmembrane tyrosine phosphatase-interacting proteins, is a new target for the metastasis-associated protein S100A4 (Mts1). J Biol Chem 2002, 277:5229-5235

92. Greenway S, van Suylen RJ, Du Marchie Sarvaas G, Kwan E, Ambartsumian N, Lukanidin E, Rabinovitch M: S100A4/Mts1 produces murine pulmonary artery changes resembling plexogenic arteriopathy and is increased in human plexogenic arteriopathy. Am J Pathol 2004, 164:253-262

93. Kwapiszewska G, Wilhelm J, Wolff S, Laumanns I, Koenig IR, Ziegler A, Seeger W, Bohle RM, Weissmann N, Fink L: Expression profiling of lasermicrodissected intrapulmonary arteries in hypoxia-induced pulmonary hypertension. Respir Res 2005, 6:109.

94. Kitao A, Sato Y, Sawada-Kitamura S, Harada K, Sasaki M, Morikawa H, Shiomi S, Honda M, Matsui O, Nakanuma Y: Endothelial to mesenchymal transition via transforming growth factor-beta1/Smad activation is associated with portal venous stenosis in idiopathic portal hypertension. Am J Pathol 2009, 175:616-626.

95. Farmer DG, Kennedy S: RAGE, vascular tone and vascular disease. Pharmacol Ther 2009, 124:185-94

96. Hamilton AT, Huntley S, Tran-Gyamfi M, Baggott DM, Gordon L, Stubbs L: Evolutionary expansion and divergence in the ZNF91 subfamily of primate-specific zinc finger genes. Genome Res 2006, 16:584-594

97. Weedon MN, Lango $H$, Lindgren CM, Wallace C, Evans DM, Mangino M, Freathy RM, Perry JR, Stevens S, Hall AS, Samani NJ, Shields B, Prokopenko I, Farrall M, Dominiczak A, Johnson T, Bergmann S, Beckmann JS, Vollenweider P, Waterworth DM, Mooser V, Palmer CN, Morris AD, Ouwehand WH, Zhao JH, Li S, Loos RJ, Barroso I, Deloukas P, Sandhu MS, et al: Genome-wide association analysis identifies 20 loci that influence adult height. Nat Genet 2008, 40:575-583.

98. Dammai $V$, Subramani S: The human peroxisomal targeting signal receptor, Pex $5 \mathrm{p}$, is translocated into the peroxisomal matrix and recycled to the cytosol. Cell 2001, 105:187-196.

99. Dodt G, Braverman N, Wong C, Moser A, Moser HW, Watkins P, Valle D, Gould SJ: Mutations in the PTS1 receptor gene, PXR1, define complementation group 2 of the peroxisome biogenesis disorders. Nat Genet 1995, 9:115-125.

100. Infante JP, Huszagh VA: Zellweger syndrome knockout mouse models challenge putative peroxisomal beta-oxidation involvement in docosahexaenoic acid (22:6n-3) biosynthesis. Mol Genet Metab 2001, 72:1-7.

101. Hulshagen L, Krysko O, Bottelbergs A, Huyghe S, Klein R, Van Veldhoven PP, De Deyn PP, D'Hooge R, Hartmann D, Baes M: Absence of functional peroxisomes from mouse CNS causes dysmyelination and axon degeneration. J Neurosci 2008, 28:4015-4027.

102. Bruno S, Cercignani M, Ron MA: White matter abnormalities in bipolar disorder: a voxel-based diffusion tensor imaging study. Bipolar Disord 2008, 10:460-468.

103. Hutchinson M, Stack J, Buckley P: Bipolar affective disorder prior to the onset of multiple sclerosis. Acta Neurol Scand 1993, 88:388-393.

104. Minden SL, Schiffer RB: Affective disorders in multiple sclerosis. Review and recommendations for clinical research. Arch Neurol 1990, 47:98-104.
105. Lan MJ, Yuan P, Chen G, Manji HK: Neuronal peroxisome proliferatoractivated receptor gamma signaling: regulation by mood-stabilizer valproate. J Mol Neurosci 2008, 35:225-234.

106. Katoh M, Katoh M: STAT3-induced WNT5A signaling loop in embryonic stem cells, adult normal tissues, chronic persistent inflammation, rheumatoid arthritis and cancer (Review). Int J Mol Med 2007, 19:273-278.

107. Mizuguchi T, Furuta I, Watanabe Y, Tsukamoto K, Tomita H, Tsujihata M, Ohta T, Kishino T, Matsumoto N, Minakami H, Niikawa N, Yoshiura K: LRP5, low-density-lipoprotein-receptor-related protein 5 , is a determinant for bone mineral density. J Hum Genet 2004, 49:80-86.

108. Smith AJ, Gidley J, Sandy JR, Perry MJ, Elson CJ, Kirwan JR, Spector TD, Doherty M, Bidwell JL, Mansell JP: Haplotypes of the low-density lipoprotein receptor-related protein 5 (LRP5) gene: are they a risk factor in osteoarthritis? Osteoarthr Cartil 2005, 13:608-613.

109. Bera TK, Liu XF, Yamada M, Gavrilova O, Mezey E, Tessarollo L, Anver M, Hahn Y, Lee B, Pastan I: A model for obesity and gigantism due to disruption of the Ankrd26 gene. Proc Natl Acad Sci USA 2008, 105:270-275.

110. Belyantseva IA, Perrin BJ, Sonnemann KJ, Zhu M, Stepanyan R, McGee J, Frolenkov GI, Walsh EJ, Friderici KH, Friedman TB, Ervasti JM: Gamma-actin is required for cytoskeletal maintenance but not development. Proc Natl Acad Sci USA 2009, 106:9703-9708.

111. Sonnemann KJ, Fitzsimons DP, Patel JR, Liu Y, Schneider MF, Moss RL, Ervasti JM: Cytoplasmic gamma-actin is not required for skeletal muscle development but its absence leads to a progressive myopathy. Dev Cell 2006, 11:387-397.

112. von Arx P, Bantle S, Soldati T, Perriard JC: Dominant negative effect of cytoplasmic actin isoproteins on cardiomyocyte cytoarchitecture and function. J Cell Biol 1995, 131:1759-1773.

113. Lloyd CM, Berendse M, Lloyd DG, Schevzov G, Grounds MD: A novel role for non-muscle gamma-actin in skeletal muscle sarcomere assembly. Exp Cell Res 2004, 297:82-96.

114. Zhang K, Chen B, Wu G: Study of differential expressed genes in vascular endothelial cell line ECV304 induced by low density lipoprotein. Zhonghua Yi Xue Za Zhi 2000, 80:784-786.

115. Gey KF, Ducimetière $P$, Evans $A$, Amouyel $P$, Arveiler $D$, Ferrières J, Luc G, Kee F, Bingham A, Yarnell J, Cambien F: Low plasma retinol predicts coronary events in healthy middle-aged men: The PRIME Study. Atherosclerosis 2010, 208:270-4.

116. Frank O, Giehl M, Zheng C, Hehlmann R, Leib-Mösch C, Seifarth W: Human endogenous retrovirus expression profiles in samples from brains of patients with schizophrenia and bipolar disorders. J Virol 2005, 79:10890-10901.

117. Huang WJ, Liu ZC, Wei W, Wang GH, Wu JG, Zhu F: Human endogenous retroviral pol RNA and protein detected and identified in the blood of individuals with schizophrenia. Schizophr Res 2006, 83:193-199.

118. Plant KE, Routledge SJ, Proudfoot NJ: Intergenic transcription in the human beta-globin gene cluster. Mol Cell Biol 2001, 21:6507-6514.

119. Rice DS, Northcutt GM, Kurschner C: The Lnx family proteins function as molecular scaffolds for Numb family proteins. Mol Cell Neurosci 2001, 18:525-540.

120. Higa S, Tokoro T, Inoue E, Kitajima I, Ohtsuka T: The active zone protein CAST directly associates with Ligand-of-Numb protein X. Biochem Biophys Res Commun 2007, 354:686-692.

121. Sollerbrant K, Raschperger E, Mirza M, Engstrom U, Philipson L, Ljungdahl PO, Pettersson RF: The Coxsackievirus and adenovirus receptor (CAR) forms a complex with the PDZ domain-containing protein ligandof-numb protein-X (LNX). J Biol Chem 2003, 278:7439-7444.

122. Liu L, Liu Y, Tong W, Ye H, Zhang $X$, Cao W, Zhang Y: Pathogen burden in essential hypertension. Circ J 2007, 71:1761-1764.

123. Saeki K, Fukuyama S, Ayada T, Nakaya M, Aki D, Takaesu G, Hanada T, Matsumura Y, Kobayashi T, Nakagawa R, Yoshimura A: A major lipid raft protein raftlin modulates $T$ cell receptor signaling and enhances th17mediated autoimmune responses. J Immunol 2009, 182:5929-5937.

124. Saeki K, Miura Y, Aki D, Kurosaki T, Yoshimura A: The B cell-specific major raft protein, Raftlin, is necessary for the integrity of lipid raft and BCR signal transduction. EMBO J 2003, 22:3015-3026.

125. Annunziato F, Cosmi L, Santarlasci V, Maggi L, Liotta F, Mazzinghi B, Parente $E$, Fili $L$, Ferri $S$, Frosali $F$, Giudici $F$, Romagnani $P$, Parronchi $P$, Tonelli $F$, Maggi $E$, Romagnani S: Phenotypic and functional features of human Th17 cells. J Exp Med 2007, 204:1849-1861.

126. Pène J, Chevalier $S$, Preisser L, Vénéreau E, Guilleux MH, Ghannam $S$, Molès JP, Danger Y, Ravon E, Lesaux S, Yssel H, Gascan H: Chronically 
inflamed human tissues are infiltrated by highly differentiated Th17 lymphocytes. J Immunol 2008, 180:7423-7430.

127. Sheu L, Pasyk EA, Ji J, Huang X, Gao X, Varoqueaux F, Brose N, Gaisano HY: Regulation of insulin exocytosis by Munc13-1. J Biol Chem 2003, 278:27556-27563.

128. Abdel-Halim SM, Guenifi A, Khan A, Larsson O, Berggren PO, Ostenson CG Efendić S: Impaired coupling of glucose signal to the exocytotic machinery in diabetic GK rats: a defect ameliorated by CAMP. Diabetes 1996, 45:934-940.

129. Ling Z, Pipeleers DG: Prolonged exposure of human beta cells to elevated glucose levels results in sustained cellular activation leading to a loss of glucose regulation. J Clin Invest 1996, 98:2805-2812.

130. Betz A, Ashery U, Rickmann M, Augustin I, Neher E, Südhof TC, Rettig J, Brose N: Munc13-1 is a presynaptic phorbol ester receptor that enhances neurotransmitter release. Neuron 1998, 21:123-136.

131. Rhee JS, Betz A, Pyott S, Reim K, Varoqueaux F, Augustin I, Hesse D, Südhof TC, Takahashi M, Rosenmund C, Brose N: Beta phorbol ester- and diacylglycerol-induced augmentation of transmitter release is mediated by Munc13 s and not by PKCs. Cell 2002, 108:121-133.

132. Augustin I, Betz A, Herrmann C, Jo T, Brose N: Differential expression of two novel Munc13 proteins in rat brain. Biochem J 1999, 337(Pt 3):363-371.

133. Mogami S, Hasegawa G, Nakayama I, Asano M, Hosoda H, Kadono M, Fukui M, Kitagawa Y, Nakano K, Ohta M, Obayashi H, Yoshikawa T, Nakamura N: Killer cell immunoglobulin-like receptor genotypes in Japanese patients with type 1 diabetes. Tissue Antigens 2007, 70:506-510

134. Shastry A, Sedimbi SK, Rajalingam R, Nikitina-Zake L, Rumba I, Wigzell $H$, Sanjeevi CB: Combination of KIR 2DL2 and HLA-C1 (Asn 80) confers susceptibility to type 1 diabetes in Latvians. Int I Immunogenet 2008, 35:439-446.

135. Cirulli V, Zalatan J, McMaster M, Prinsen R, Salomon DR, Ricordi C, Torbett BE, Meda P, Crisa L: The class I HLA repertoire of pancreatic islets comprises the nonclassical class Ib antigen HLA-G. Diabetes 2006, 55:1214-1222.

136. Eike MC, Becker T, Humphreys K, Olsson M, Lie BA: Conditional analyses on the T1DGC MHC dataset: novel associations with type 1 diabetes around HLA-G and confirmation of HLA-B. Genes Immun 2009, 10:56-67.

137. Corradi JP, Ravyn V, Robbins AK, Hagan KW, Peters MF, Bostwick R, Buono RJ, Berrettini WH, Furlong ST: Alternative transcripts and evidence of imprinting of GNAL on 18p11.2. Mol Psychiatry 2005, 10:1017-1025.

138. Martín MC, Martinez A, Mendoza JL, Taxonera C, Díaz-Rubio M, FernándezArquero $\mathrm{M}$, de la Concha EG, Urcelay E: Influence of the inducible nitric oxide synthase gene (NOS2A) on inammatory bowel disease susceptibility. Immunogenetics 2007, 59:833-837.

139. Singer II, Kawka DW, Scott S, Weidner JR, Mumford RA, Riehl TE, Stenson WF: Expression of inducible nitric oxide synthase and nitrotyrosine in colonic epithelium in inflammatory bowel disease. Gastroenterology 1996, 111:871-885

140. Lengyel C, Virág L, Bíró T, Jost N, Magyar J, Biliczki P, Kocsis E, Skoumal R, Nánási PP, Tóth M, Kecskeméti V, Papp JG, Varró A: Diabetes mellitus attenuates the repolarization reserve in mammalian heart. Cardiovasc Res 2007, 73:512-520.

141. Hoshi N, Takahashi H, Shahidullah M, Yokoyama S, Higashida H: KCR1, a membrane protein that facilitates functional expression of noninactivating $\mathrm{K}+$ currents associates with rat EAG voltage-dependent $\mathrm{K}+$ channels. J Biol Chem 1998, 273:23080-23085.

142. Veglio M, Bruno G, Borra M, Macchia G, Bargero G, D'Errico N, Pagano GF, Cavallo-Perin P: Prevalence of increased QT interval duration and dispersion in type 2 diabetic patients and its relationship with coronary heart disease: a population-based cohort. J Intern Med 2002, 251:317-324.

143. Holmkvist J, Banasik K, Andersen G, Unoki H, Jensen TS, Pisinger C, BorchJohnsen K, Sandbaek A, Lauritzen T, Brunak S, Maeda S, Hansen T, Pedersen O: The type 2 diabetes associated minor allele of rs2237895 KCNQ1 associates with reduced insulin release following an oral glucose load. PLOS ONE 2009, 4:e5872.

144. Belenkaya TY, Wu Y, Tang X, Zhou B, Cheng L, Sharma YV, Yan D, Selva EM, Lin $X$ : The retromer complex influences Wht secretion by recycling wntless from endosomes to the trans-Golgi network. Dev Cell 2008, 14:120-131.

145. Clevers H: Wnt/beta-catenin signaling in development and disease. Cell 2006, 127:469-480
146. Zandi PP, Belmonte PL, Willour VL, Goes FS, Badner JA, Simpson SG Gershon ES, McMahon FJ, DePaulo JRJ, Potash JB: Association study of Wnt signaling pathway genes in bipolar disorder. Arch Gen Psychiatry 2008, 65(7):785-93

147. Twells RC, Mein CA, Payne F, Veijola R, Gilbey M, Bright M, Timms A, Nakagawa Y, Snook H, Nutland S, Rance HE, Carr P, Dudbridge F, Cordell HJ, Cooper J, Tuomilehto-Wolf E, Tuomilehto J, Phillips M, Metzker M, Hess JF, Todd JA: Linkage and association mapping of the LRP5 locus on chromosome 11q13 in type 1 diabetes. Hum Genet 2003, 113:99-105.

148. Figueroa DJ, Hess JF, Ky B, Brown SD, Sandig V, Hermanowski-Vosatka A, Twells RC, Todd JA, Austin CP: Expression of the type I diabetesassociated gene LRP5 in macrophages, vitamin A system cells, and the Islets of Langerhans suggests multiple potential roles in diabetes. $J$ Histochem Cytochem 2000, 48:1357-1368.

149. Leo D, Adriani W, Cavaliere C, Cirillo G, Marco EM, Romano E, di Porzio U, Papa M, Perrone-Capano C, Laviola G: Methylphenidate to adolescent rats drives enduring changes of accumbal Htr7 expression: implications for impulsive behavior and neuronal morphology. Genes Brain Behav 2009, 8:356-368

150. Ikeda M, Iwata N, Kitajima T, Suzuki T, Yamanouchi Y, Kinoshita Y, Ozaki N: Positive association of the serotonin 5-HT7 receptor gene with schizophrenia in a Japanese population. Neuropsychopharmacology 2006, 31:866-871.

151. Fernández-Medarde A, Porteros A, de las Rivas J, Núñez A, Fuster J J, Santos E: Laser microdissection and microarray analysis of the hippocampus of Ras-GRF1 knockout mice reveals gene expression changes affecting signal transduction pathways related to memory and learning. Neuroscience 2007, 146:272-285.

152. Jean L, Risler JL, Nagase T, Coulouarn C, Nomura N, Salier JP: The nuclear protein PH5P of the inter-alpha-inhibitor superfamily: a missing link between poly(ADP-ribose)polymerase and the interalpha-inhibitor family and a novel actor of DNA repair? FEBS Lett 1999, 446:6-8

153. Shimokawa H, Rashid M: Development of Rho-kinase inhibitors for cardiovascular medicine. Trends Pharmacol Sci 2007, 28:296-302.

154. Blaschke S, Middel P, Dorner BG, Blaschke V, Hummel KM, Kroczek RA, Reich K, Benoehr P, Koziolek M, Müller GA: Expression of activationinduced, $\mathrm{T}$ cell-derived, and chemokine-related cytokine/lymphotactin and its functional role in rheumatoid arthritis. Arthritis Rheum 2003, 48:1858-1872.

155. Yoshida T, Imai T, Kakizaki M, Nishimura M, Takagi S, Yoshie O: Identification of single C motif-1/lymphotactin receptor XCR1. J Biol Chem 1998, 273:16551-16554

156. Wang CR, Liu MF, Huang YH, Chen HC: Up-regulation of XCR1 expression in rheumatoid joints. Rheumatology (Oxford) 2004, 43:569-573.

157. Mojarrabi B, Mackenzie PI: Characterization of two UDP glucuronosyltransferases that are predominantly expressed in human colon. Biochem Biophys Res Commun 1998, 247:704-709.

158. Gupta RP, Hollis BW, Patel SB, Patrick KS, Bell NH: CYP3A4 is a human microsomal vitamin D 25-hydroxylase. J Bone Miner Res 2004, 19:680-688.

159. Mollet J, Giurgea I, Schlemmer D, Dallner G, Chretien D, Delahodde A, Bacq D, de Lonlay P, Munnich A, Rötig A: Prenyldiphosphate synthase, subunit 1 (PDSS1) and OH-benzoate polyprenyltransferase (COQ2) mutations in ubiquinone deficiency and oxidative phosphorylation disorders. J Clin Invest 2007, 117:765-772.

160. McFadden SA: Phenotypic variation in xenobiotic metabolism and adverse environmental response: focus on sulfur-dependent detoxification pathways. Toxicology 1996, 111:43-65.

161. Salman ED, Kadlubar SA, Falany CN: Expression and localization of cytosolic sulfotransferase (SULT) 1A1 and SULT1A3 in normal human brain. Drug Metab Dispos 2009, 37:706-709.

162. Yasuda S, Yasuda T, Hui Y, Liu MY, Suiko M, Sakakibara Y, Liu MC: Concerted action of the cytosolic sulfotransferase, SULT1A3, and catechol-O-methyltransferase in the metabolism of dopamine in SK-NMC human neuroblastoma cells. Neurosci Res 2009, 64:273-279.

163. Berk M, Dodd S, Kauer-Sant'anna M, Malhi GS, Bourin M, Kapczinski F, Norman T: Dopamine dysregulation syndrome: implications for a dopamine hypothesis of bipolar disorder. Acta Psychiatr Scand Suppl 2007, 41-49.

164. Gainetdinov RR: Mesolimbic dopamine in obesity and diabetes. Am J Physiol Regul Integr Comp Physiol 2007, 293:R601-602. 
165. Sardiello M, Cairo S, Fontanella B, Ballabio A, Meroni G: Genomic analysis of the TRIM family reveals two groups of genes with distinct evolutionary properties. BMC Evol Biol 2008, 8:225.

166. Liu ST, Hittle JC, Jablonski SA, Campbell MS, Yoda K, Yen TJ: Human CENP-I specifies localization of CENP-F, MAD1 and MAD2 to kinetochores and is essential for mitosis. Nat Cell Biol 2003, 5:341-345.

167. Chiba S, Ikeda M, Katsunuma K, Ohashi K, Mizuno K: MST2- and Furrymediated activation of NDR1 kinase is critical for precise alignment of mitotic chromosomes. Curr Biol 2009, 19:675-681.

168. Li L, Shi Y, Wu H, Wan B, Li P, Zhou L, Shi H, Huo K: Hepatocellular carcinoma-associated gene 2 interacts with MAD2L2. Mol Cell Biochem 2007, 304:297-304

169. Ito M, Nakano T, Erdodi F, Hartshorne DJ: Myosin phosphatase: structure, regulation and function. Mol Cell Biochem 2004, 259:197-209.

170. Okamoto R, Kato T, Mizoguchi A, Takahashi N, Nakakuki T, Mizutani H, Isaka N, Imanaka-Yoshida K, Kaibuchi K, Lu Z, Mabuchi K, Tao T, Hartshorne DJ, Nakano T, Ito M: Characterization and function of MYPT2, a target subunit of myosin phosphatase in heart. Cell Signal 2006 18:1408-1416.

171. Sato T, Konomi K, Yamasaki S, Aratani S, Tsuchimochi K, Yokouchi M, Masuko-Hongo K, Yagishita N, Nakamura H, Komiya S, Beppu M, Aoki H, Nishioka K, Nakajima T: Comparative analysis of gene expression profiles in intact and damaged regions of human osteoarthritic cartilage. Arthritis Rheum 2006, 54:808-817.

172. Bleich A, Hopf S, Hedrich HJ, van Lith HA, Li F, Balfour Sartor R, Mähler M Genetic dissection of granulomatous enterocolitis and arthritis in the intramural peptidoglycan-polysaccharide-treated rat model of IBD. Inamm Bowel Dis 2009, 15:1794-802.

173. Kerr JR: Pathogenesis of parvovirus B19 infection: host gene variability, and possible means and effects of virus persistence. J Vet Med B Infect Dis Vet Public Health 2005, 52:335-339.

174. Cénit M, Blanco-Kelly F, de Las Heras V, Bartolomé M, de la Concha E, Urcelay E, Arroyo R, Marténez A: Glypican 5 is an interferon-beta response gene: a replication study. Mult Scler 2009, 15:913-917.

175. Baranzini SE, Wang J, Gibson RA, Galwey N, Naegelin Y, Barkhof F, Radue EW, Lindberg RL, Uitdehaag BM, Johnson MR, Angelakopoulou A, Hall L, Richardson JC, Prinjha RK, Gass A, Geurts JJ, Kragt J, Sombekke M, Vrenken H, Qualley P, Lincoln RR, Gomez R, Caillier SJ, George MF, Mousavi H, Guerrero R, Okuda DT, Cree BA, Green AJ, Waubant E, et al: Genome-wide association analysis of susceptibility and clinical phenotype in multiple sclerosis. Hum Mol Genet 2009, 18:767-778.

176. Nokelainen $P$, Peltoketo $H$, Vihko R, Vihko P: Expression cloning of a novel estrogenic mouse 17 beta-hydroxysteroid dehydrogenase/17ketosteroid reductase (m17HSD7), previously described as a prolactin receptor-associated protein (PRAP) in rat. Mol Endocrinol 1998, 12:1048-1059

177. Ohnesorg T, Keller B, Hrabé de Angelis M, Adamski J: Transcriptional regulation of human and murine 17beta-hydroxysteroid dehydrogenase type-7 confers its participation in cholesterol biosynthesis. $J \mathrm{Mol}$ Endocrinol 2006, 37:185-197.

178. lams SG, Wexler BC: Inhibition of the development of spontaneous hypertension in $\mathrm{SH}$ rats by gonadectomy or estradiol. J Lab Clin Med 1979, 94:608-616.

179. Mercuro G, Zoncu S, Piano D, Pilia I, Lao A, Melis GB, Cherchi A: Estradiol17beta reduces blood pressure and restores the normal amplitude of the circadian blood pressure rhythm in postmenopausal hypertension. Am J Hypertens 1998, 11:909-913.

180. Garcia PM, Giménez J, Bonacasa B, Carbonell LF, Miguel SG, Quesada T, Hernández l: 17beta-estradiol exerts a beneficial effect on coronary vascular remodeling in the early stages of hypertension in spontaneously hypertensive rats. Menopause 2005, 12:453-459.

181. Pietranera L, Saravia FE, Roig P, Lima A, De Nicola AF: Protective effects of estradiol in the brain of rats with genetic or mineralocorticoid-induced hypertension. Psychoneuroendocrinology 2008, 33:270-281.

182. Honigberg L, Kenyon C: Establishment of left/right asymmetry in neuroblast migration by UNC-40/DCC, UNC-73/Trio and DPY-19 proteins in C. elegans. Development 2000, 127:4655-4668.

183. el Gabalawy H, Canvin J, Ma GM, Van der Vieren M, Hoffman P, Gallatin M, Wilkins J: Synovial distribution of alpha d/CD18, a novel leukointegrin. Comparison with other integrins and their ligands. Arthritis Rheum 1996, 39:1913-1921.
184. Highton J, Carlisle B, Palmer DG: Changes in the phenotype of monocytes/macrophages and expression of cytokine mRNA in peripheral blood and synovial fluid of patients with rheumatoid arthritis. Clin Exp Immunol 1995, 102:541-546.

185. Lisnic B, Svetec IK, Stafa A, Zgaga Z: Size-dependent palindrome-induced intrachromosomal recombination in yeast. DNA Repair (Amst) 2009, 8:383-389.

186. Sasaoka T, Kimura A, Hohta SA, Fukuda N, Kurosawa T, Izumi T: Polymorphisms in the platelet-endothelial cell adhesion molecule-1 (PECAM-1) gene, Asn563Ser and Gly670Arg, associated with myocardial infarction in the Japanese. Ann N Y Acad Sci 2001, 947:259-269.

187. Elrayess MA, Webb KE, Bellingan GJ, Whittall RA, Kabir J, Hawe E, Syvänne M, Taskinen MR, Frick MH, Nieminen MS, Kesäniemi YA, Pasternack A, Miller GJ, Humphries SE: R643G polymorphism in PECAM-1 influences transendothelial migration of monocytes and is associated with progression of CHD and CHD events. Atherosclerosis 2004, 177:127-135

188. Fang L, Wei H, Chowdhury SH, Gong N, Song J, Heng CK, Sethi S, Koh TH, Chatterjee S: Association of Leu125Val polymorphism of platelet endothelial cell adhesion molecule-1 (PECAM-1) gene \& soluble level of PECAM-1 with coronary artery disease in Asian Indians. Indian J Med Res 2005, 121:92-99.

189. Schaub MA, Kaplow IM, Sirota M, Do CB, Butte AJ, Batzoglou S: A classifierbased approach to identify genetic similarities between diseases. Bioinformatics 2009, 25:121-29.

190. Goldstein BI, Fagiolini A, Houck P, Kupfer DJ: Cardiovascular disease and hypertension among adults with bipolar I disorder in the United States. Bipolar Disord 2009, 11:657-662.

191. Ponsonby AL, Lucas RM, van der Mei IA: UVR, vitamin D and three autoimmune diseases-multiple sclerosis, type 1 diabetes, rheumatoid arthritis. Photochem Photobiol 2005, 81:1267-1275.

192. Chatterjee M: Vitamin D and genomic stability. Mutat Res 2001, 475:69-87.

193. Grant WB: Hypothesis-ultraviolet- $B$ irradiance and vitamin D reduce the risk of viral infections and thus their sequelae, including autoimmune diseases and some cancers. Photochem Photobiol 2008, 84:356-365.

194. Cousineau I, Abaji C, Belmaaza A: BRCA1 regulates RAD51 function in response to DNA damage and suppresses spontaneous sister chromatid replication slippage: implications for sister chromatid cohesion, genome stability, and carcinogenesis. Cancer Res 2005, 65:11384-11391

195. Jin H, Selfe J, Whitehouse C, Morris JR, Solomon E, Roberts RG: Structural evolution of the BRCA1 genomic region in primates. Genomics 2004, 84:1071-1082.

196. Puget N, Gad S, Perrin-Vidoz L, Sinilnikova OM, Stoppa-Lyonnet D, Lenoir GM, Mazoyer S: Distinct BRCA1 rearrangements involving the BRCA1 pseudogene suggest the existence of a recombination hot spot. Am J Hum Genet 2002, 70:858-865.

197. Staff S, Nupponen NN, Borg A, Isola JJ, Tanner MM: Multiple copies of mutant BRCA1 and BRCA2 alleles in breast tumors from germ-line mutation carriers. Genes Chromosomes Cancer 2000, 28:432-442.

198. Banerjee A, Benedict WF: Production of sister chromatid exchanges by various cancer chemotherapeutic agents. Cancer Res 1979, 39:797-799.

199. Berger SH, Pittman DL, Wyatt MD: Uracil in DNA: consequences for carcinogenesis and chemotherapy. Biochem Pharmacol 2008, 76:697-706

200. Alkan C, Kidd JM, Marques-Bonet T, Aksay G, Antonacci F, Hormozdiari F Kitzman JO, Baker C, Malig M, Mutlu O, Sahinalp SC, Gibbs RA, Eichler EE: Personalized copy number and segmental duplication maps using nextgeneration sequencing. Nat Genet 2009, 41:1061-1067.

201. Redon R, Ishikawa S, Fitch KR, Feuk L, Perry GH, Andrews TD, Fiegler $H$, Shapero MH, Carson AR, Chen W, Cho EK, Dallaire S, Freeman JL, González JR, Gratacòs M, Huang J, Kalaitzopoulos D, Komura D, MacDonald JR, Marshall CR, Mei R, Montgomery L, Nishimura K, Okamura K, Shen F, Somerville MJ, Tchinda J, Valsesia A, Woodwark C, Yang F, et al: Global variation in copy number in the human genome. Nature 2006, 444:444-454.

202. Perry GH, Ben-Dor A, Tsalenko A, Sampas N, Rodriguez-Revenga L, Tran CW, Scheffer A, Steinfeld I, Tsang P, Yamada NA, Park HS, Kim JI, Seo JS, Yakhini Z, Laderman S, Bruhn L, Lee C: The fine-scale and complex architecture of human copy-number variation. Am J Hum Genet 2008, 82:685-695.

203. Shaikh TH, Gai X, Perin JC, Glessner JT, Xie H, Murphy K, O'Hara R, Casalunovo T, Conlin LK, D'Arcy M, Frackelton EC, Geiger EA, Haldeman- 
Englert C, Imielinski M, Kim CE, Medne L, Annaiah K, Bradfield JP, Dabaghyan E, Eckert A, Onyiah CC, Ostapenko S, Otieno FG, Santa E, Shaner JL, Skraban R, Smith RM, Elia J, Goldmuntz E, Spinner NB, et al: High-resolution mapping and analysis of copy number variations in the human genome: a data resource for clinical and research applications. Genome Res 2009, 19:1682-1690.

204. de Smith AJ, Tsalenko A, Sampas N, Scheffer A, Yamada NA, Tsang P, BenDor A, Yakhini Z, Ellis RJ, Bruhn L, Laderman S, Froguel P, Blakemore Al: Array CGH analysis of copy number variation identifies 1284 new genes variant in healthy white males: implications for association studies of complex diseases. Hum Mol Genet 2007, 16:2783-2794.

205. Cooper GM, Zerr T, Kidd JM, Eichler EE, Nickerson DA: Systematic assessment of copy number variant detection via genome-wide SNP genotyping. Nat Genet 2008, 40:1199-1203.

206. McCarroll SA, Kuruvilla FG, Korn JM, Cawley S, Nemesh J, Wysoker A, Shapero MH, de Bakker PI, Maller JB, Kirby A, Elliott AL, Parkin M, Hubbell E, Webster T, Mei R, Veitch J, Collins PJ, Handsaker R, Lincoln S, Nizzari M, Blume J, Jones KW, Rava R, Daly MJ, Gabriel SB, Altshuler D: Integrated detection and population-genetic analysis of SNPs and copy number variation. Nat Genet 2008, 40:1166-1174.

207. Woodward EJ, Thomas JW: Multiple germline kappa light chains generate anti-insulin B cells in nonobese diabetic mice. J Immunol 2005, 175:1073-1079.

208. Martinet W, Schrijvers DM, De Meyer GR, Herman AG, Kockx MM: Western array analysis of human atherosclerotic plaques: downregulation of apoptosis-linked gene 2. Cardiovasc Res 2003, 60:259-267.

209. Draviam VM, Shapiro I, Aldridge B, Sorger PK: Misorientation and reduced stretching of aligned sister kinetochores promote chromosome missegregation in EB1- or APC-depleted cells. EMBO J 2006, 25:2814-2827.

210. Ménard V, Eap O, Harvey M, Guillemette C, Lévesque E: Copy-number variations (CNVs) of the human sex steroid metabolizing genes UGT2B17 and UGT2B28 and their associations with a UGT2B15 functional polymorphism. Hum Mutat 2009, 30:1310-1319

211. Kobayashi K, Yagasaki M, Harada N, Chichibu K, Hibi T, Yoshida T, Brown WR, Morikawa M: Detection of Fcgamma binding protein antigen in human sera and its relation with autoimmune diseases. Immunol Lett 2001, 79:229-235.

212. Kuhl A, Melberg A, Meinl E, Nürnberg G, Nürnberg P, Kehrer-Sawatzki $H$, Jenne DE: Myofibrillar myopathy with arrhythmogenic right ventricular cardiomyopathy 7: corroboration and narrowing of the critical region on 10q22.3. Eur J Hum Genet 2008, 16:367-373.

213. Hattori F, Murayama N, Noshita T, Oikawa S: Mitochondrial peroxiredoxin-3 protects hippocampal neurons from excitotoxic injury in vivo. J Neurochem 2003, 86:860-868.

214. Li L, Rasul I, Liu J, Zhao B, Tang R, Premont RT, Suo WZ: Augmented axonal defects and synaptic degenerative changes in female GRK5 deficient mice. Brain Res Bull 2009, 78:145-151.

215. Koshelev YA, Kiselev SL, Georgiev GP: Interaction of the S100A4 (Mts1) protein with septins Sept2, Sept6, and Sept7 in vitro. Dokl Biochem Biophys 2003, 391:195-197.

216. Park KS, Park JH, Song YW: Inhibitory NKG2A and activating NKG2 D and NKG2C natural killer cell receptor genes: susceptibility for rheumatoid arthritis. Tissue Antigens 2008, 72:342-346.

217. Grose RH, Thompson FM, Baxter AG, Pellicci DG, Cummins AG: Deficiency of invariant NK T cells in Crohn's disease and ulcerative colitis. Dig Dis Sci 2007, 52:1415-1422

\section{Pre-publication history}

The pre-publication history for this paper can be accessed here: http://www.biomedcentral.com/1741-7015/9/12/prepub

doi:10.1186/1741-7015-9-12

Cite this article as: Ross: Evidence for somatic gene conversion and deletion in bipolar disorder, Crohn's disease, coronary artery disease, hypertension, rheumatoid arthritis, type-1 diabetes, and type- 2 diabetes. BMC Medicine 2011 9:12. 